\title{
PHENOMENOLOGY OF RAPID PROJECTILE PENETRATION INTO GRANULAR SOILS
}

\author{
Mehdi Omidvar ${ }^{1}$, Jeanne Doreau Malioche ${ }^{2}$, Stephan Bless ${ }^{1}$, DSc, and Magued Iskander ${ }^{1}, \mathrm{PhD}^{\S}$ \\ ${ }^{1}$ New York University, USA \\ ${ }^{2}$ Ecole Nationale des Travaux Publics de l'Etat, Vaulx-en-Velin, France. Formerly visiting scholar, New \\ York University, USA
}

\begin{abstract}
Eighty subscale penetration tests were performed to investigate penetration phenomenology in granular media, with impact velocities in the range of 70-300 m/s. The parameter space consisted of (1) four natural and synthetic granular materials, including Ottawa sand, crushed fused quartz, aragonite, and crushed coral, (2) loose and dense packings, (3) dry and wet targets, and (4) four different projectiles, including spheres and long rods with conical, hemispherical and blunt nose shapes. Two techniques were employed to obtain penetration time histories, including photonic Doppler velocimetry for high velocity impact tests, and high speed imaging for low velocity impact tests. Penetration time histories were differentiated to obtain velocity and acceleration time histories. Analysis of the time histories revealed that the role of nose shape, packing density, and saturation is material dependent. Silica sands and calcareous sands showed contrasting behavior across the parameter space considered. These observations point to the significance of particle crushing in rapid penetration into granular media.
\end{abstract}

Keywords: Photonic Doppler velocimetry; High-speed imaging; Sand; Granular media; Impact; Projectile

$\S$ Professor and Head, Civil \& Urban Engineering Department, Polytechnic School of Engineering, New York University. Six Metrotech Center, Brooklyn, NY 11201. Tel: (718) 260-3016, Fax: (718) 2603433, Email: Iskander@nyu.edu (Corresponding Author). 


\section{Introduction}

There has been a recent surge of interest in penetration of granular materials. Impact and penetration into granular media is important for many engineering applications, including subsurface investigations, planetary impact, and offshore foundations and anchors, among others (Omidvar et al. 2014). Many aspects of penetration mechanics have been addressed in recent literature. A general picture is emerging in which there appears to be several distinct regimes in the global records of penetration into granular media. These regimes appear with different fidelity in different materials, and they appear to depend on the penetration velocity. The existence of different penetration regimes may point to changes in energy transfer mechanisms at different stages of penetration. This paper is an effort to further investigate these regimes.

The study of rapid penetration into granular media is closely related to their high strain rate response (Omidvar et al. 2012). Thus study of penetration effects provides both qualitative and quantitative insights into the mechanical properties of granular materials at high stresses and high strain rates. For example it has been shown that during penetration of an intruder in granular media, networks of stressed particles known as force chains transfer the intruder load to the target media at particle contacts (e.g., Clark et al. 2014). As the magnitude of load carried by the particles increases, displacement of particles results in buckling of these force chains. Load is therefore redistributed along other force chains as new contacts form. Formation and buckling of force chains appears dependent on the penetration velocity due to the time scale associated with these phenomena. Investigating these hypotheses requires observations of penetration dynamics across a wide range of penetration velocities.

In this paper, results of experiments performed with projectiles penetrating various granular media are reported. Two methods were employed to measure time history of projectile penetration; photonic Doppler velocimetry (PDV) for spherical projectiles impacting at $300 \mathrm{~m} / \mathrm{s}$ and high-speed imaging (HSI) for rod projectiles penetrating at $50-100 \mathrm{~m} / \mathrm{sec}$. Three natural sands and one synthetic material are tested, and the penetration histories are recorded. First, the experimental setups used to obtain penetration time histories in various materials and using different projectiles are briefly described. Next, observations of penetration dynamics along with general patterns observed from the tests in various materials are reported. Finally, the observed response is related to the phenomenology of rapid penetration into granular media. 


\section{Experiments}

\subsection{Granular media}

Four different granular media were tested in this study (Fig. 1). The materials were selected to cover a range of parameters representative of natural and synthetic granular media, including specific gravity, packing density, particle shape, mineralogy, and internal flaws. Several standard characterization tests were performed on the tested media, including minimum and maximum density measurements according to ASTM D4254 and ASTM D4253, specific gravity according to ASTM 854, and particle size distribution according to ASTM 6913. In addition to the aforementioned characterization, typical particle shapes were also characterized using a dynamic imaging particle size analyzer (Sympatec QicPic). Typical 2D projections of particle shapes corresponding to the median diameter, by weight, known as $d_{50}$ were obtained (Fig 2). Particles were characterized using sphericity, $\psi$, and aspect ratio, $A_{R}$. Sphericity is defined as the ratio of the surface area of a sphere with the same volume as the given particle to the surface area of the particle, and aspect ratio is defined as the ratio of the largest diameter to the smallest diameter orthogonal to it. Distribution of sphericity with particle size is shown in Fig 2 for the four tested materials, which are as follows:

- Ottawa sand, which is a siliceous sand with a particle specific gravity of 2.65. The size distribution of the particles is shown in Fig 1. Ottawa sand has a narrow size distribution, classified as poorly graded sand (SP) in the Unified Soil Classification System (USCS) (ASTM D2487). Ottawa sand is comprised mainly of round particles (Fig. 2), having a $d_{50}$ of $0.65 \mathrm{~mm}$, median sphericity of 0.90 . Minimum and maximum densities of the Ottawa sand were 1.56 $\mathrm{g} / \mathrm{cm}^{3}$ and $1.83 \mathrm{~g} / \mathrm{cm}^{3}$, respectively.

- Crushed fused quartz, a product of grinding fused silica glass, is also classified as SP according to USCS. Crushed fused quartz consists of $99 \% \mathrm{SiO}_{2}$, and has a specific gravity of 2.20 (Guzman et al 2014). Unlike Ottawa sand, it is amorphous; presumably the grains are much stronger, since there are no sub-grains that can break apart. The material is comprised of angular particles, having $d_{50}$ of $0.21 \mathrm{~mm}$, with a median sphericity of 0.83 , but with a broad distribution of particles with smaller sphericity down to approximately 0.45 . Minimum and maximum densities of the tested crushed fused quartz were $0.99 \mathrm{~g} / \mathrm{cm}^{3}$ and $1.31 \mathrm{~g} / \mathrm{cm}^{3}$, respectively.

- Aragonite sand is an oolitic calcium carbonate based granular material with round particle shapes, as shown in Fig 2. Aragonite results from precipitation of calcite; the particles have a 
specific gravity of 2.74, which is higher than the other materials tested. Aragonite was chosen because it resembles the sphericity of Ottawa sand, but is more susceptible to crushing. The tested Argonite has a $d_{50}$ of 0.38 , with an average sphericity of 0.88 and aspect ratio of 0.74 . It is classified as SP according to USCS. Minimum and maximum densities of the aragonite sand were $1.55 \mathrm{~g} / \mathrm{cm}^{3}$ and $1.73 \mathrm{~g} / \mathrm{cm}^{3}$, respectively.

- Crushed coral is a calcareous granular material consisting mainly of calcium carbonate or calcite, with marine origin. The material was chosen due to its angularity which resembles fused quartz, and susceptibility to crushing, as the particles have significantly lower strength compared to silica based natural sand. Typical particle shapes, shown in Fig 2, reveal that the material is somewhat less angular than fused quartz. The tested material has a $d_{50}$ of 0.36 , with an average sphericity of 0.84 and aspect ratio of 0.74 . The crushed coral used in this study is classified as poorly-graded sand (SP) according to USCS, and has a specific gravity of 2.66. Minimum and maximum densities of the crushed coral were $1.44 \mathrm{~g} / \mathrm{cm}^{3}$ and $1.73 \mathrm{~g} / \mathrm{cm}^{3}$, respectively.

Samples were prepared in loose and dense packings by means of pluviation (raining). Consistent packing can be produced throughout the target by allowing granular media to be pluviated form a controlled height, to pass through a set of sieves, and to sediment in the container, according to guidelines suggested by Raad and Tumay (1987). Reducing the pluviation rate results in increase in density of the target media, whereas loose packing can be achieved by increasing the pluviation rate. In this paper, loose and dense packings were achieved by pluviating at a rate of 130 and 6 $\mathrm{g} / \mathrm{cm}^{2} / \mathrm{min}$. Consistency of the resulting packing density was verified in trial tests by placing metal cans within the target during pluviation and calculating density of retrieved samples. Samples with a coefficient of variation of approximately $2-5 \%$ of the calculated densities, were achieved.

Wet samples were prepared by first preparing dry targets following the pluviation method described above, then adding water from the bottom of the samples, at a rate of $30 \mathrm{cc} / \mathrm{min}$, in order to ensure that pores were replaced by water to the extent possible. Visual inspection of the targets revealed that the samples were nearly saturated, although few pores remained unsaturated. Typical degrees of saturation exceeded 0.96 for the tested materials; samples were assumed to be in a 'wet' state. 


\subsection{Penetrators}

The penetrator designs are shown in Fig 3. Rods with three different nose shapes were considered: hemispherical, conical, and blunt, along with a sphere. The rods were precision machined from 6061 aluminum, to a diameter of $10 \mathrm{~mm}$, and a length-to-diameter ratio of 10 . The blunt, hemispherical, and conical rods weighed 16.64, 16.03, and $16.10 \mathrm{~g}$, respectively. In order to increase trajectory stability and decrease mass, a counter bore was drilled in the backs, to a depth of $65 \mathrm{~mm}$. The low impact velocities employed for rods did not result in high enough stresses to cause wear and deformation of the rods, which was confirmed by post mortem visual inspection; thus the same projectiles were used throughout the program. Motion of the projectiles following full embedment was tracked by fitting a slender rod to the end of the projectile, which extended to a length of $100 \mathrm{~mm}$ beyond it. In order to provide reference points for tracking movement, the projectile and the extending follower were marked with stripes along their length using nonmetallic black spray paint.

High velocity tests were conducted with spheres made of stainless steel, having a diameter of 14 $\mathrm{mm}$ and a mass of $11.17 \mathrm{~g}$. In the high velocity tests, wear was evident in post mortem inspection, and a new sphere was used in each test.

\subsection{Projectile launchers}

Two different electro-pneumatic accelerators were employed, one for the lower velocity tests, and the other for higher velocities. The lower velocity tests in the range of $50-100 \mathrm{~m} / \mathrm{s}$ were performed using a single stage electro-pneumatic accelerator, described by Cave et al. (2014). The higher velocity tests $(300 \mathrm{~m} / \mathrm{s})$ were performed using a single stage double burst diaphragm electro-pneumatic accelerator. This launcher consisted of two chambers, separated by a burst diaphragm designed to burst at a prescribed pressure. The setup therefore allowed achieving desired pressures in shorter times, allowing for accelerating the projectiles to higher impact velocities. Further details of the second launcher are available in Peden et al. (2014).

\subsection{Measurements}

Two optical diagnostic techniques were employed to measure time history of projectile penetration into dry and wet granular media. The first method was Photonic Doppler Velocimetry (PDV), which was used for spherical projectiles impacting at $300 \mathrm{~m} / \mathrm{s}$. The second method was high-speed imaging (HSI) which was used for rod projectiles. 
PDV is a heterodyne technique, in which Doppler shifted coherent light reflected from a moving object is collected and used to measure velocity of the moving object with high temporal resolution. In penetration tests, coherent laser light was projected onto the rear of the projectile, and the reflected light was continuously collected. The interference of the two signals produced an interference pattern resulting in signals with the sum and difference of the emitted and reflected light frequencies. The signal produced at the difference, known as the beat signal, was used to obtain the velocity of the moving projectile. First, the beat frequency, $f_{b}$, is measured in the tests, and is related to the Doppler shifted frequency, $f_{D}$, and the original laser source wave frequency, $f_{0}$, as follows

$$
f_{b}=\left|f_{D}-f_{0}\right|
$$

The time varying beat frequency can be related to the instantaneous velocity of the projectile, $v(t)$, using the following relationship:

$$
\begin{aligned}
& f_{b}(t)=2\left[\frac{v(t)}{c}\right] f_{0}=2\left[\frac{v(t)}{0}\right] \\
& v(t)=1 / 2{ }_{0} f_{b}(t)
\end{aligned}
$$

where $c$ is the light wave speed, and $\lambda_{0}$ is the wavelength of the laser light source. Eq. (2) can therefore be used to calculate the velocity of the projectile during penetration. Details of the PDV setup used to obtain velocity time history of penetration into granular media reported in this study can be found in Peden et al. (2014).

The PDV setup described above was employed in measurement of tests performed at $300 \mathrm{~m} / \mathrm{s}$. The reflected laser light was tracked during penetration, from impact down to approximately 25$50 \mathrm{~m} / \mathrm{s}$, after which the signal was usually lost due to the collapse of the cavity in the sand behind the projectile. In some tests, signals were lost, and retrieved at later stages of penetration. The method became increasingly difficult as the penetrator approached terminal penetration depth.

The HSI technique was employed in order to obtain better data at relatively greater depths and lower velocities. In these tests rod penetrators were used. Tracking the marks on the penetrator and its follower provided the penetration time history. A single differentiation then yielded the velocity time history. 
174 The high-speed camera used to acquire images of the penetrator was an NAC HX5 unit. A Nikkor

$17555 \mathrm{~mm}, 1.2 \mathrm{f} / \mathrm{stop}$ (aperture) lens was mounted on the camera, along with a close up lens with a 176 magnification of +2 , to increase the spatial resolution of the images in physical units. The lens 177 was adjusted to an aperture opening corresponding to $f / 5.6$. The camera was operated at an 178 imaging frequency of $50 \mathrm{kHz}$ in the tests reported herein, which resulted in a field of view of 384 179 by 304 pixels (vertical x horizontal). An exposure time of $5 \mu$ s was used to prevent image 180 blurring. The setup is shown in Fig 4. In order to deliver adequate lighting to the penetrator for 181 high-speed imaging, a set of two $500 \mathrm{~W}$ and one $250 \mathrm{~W}$ tungsten halogen lights were used to front 182 light the projectile. The setup described above resulted in a spatial resolution of $54 \mu \mathrm{m}$ and a 183 temporal resolution of $20 \mu \mathrm{s}$. Snapshots of the penetrator traversing through the field of view of 184 the high-speed camera are shown in Fig 5 for penetration of blunt nose shaped rod into dry fused 185 quartz.

186 In the HSI tests the field of view of the camera was constricted to a region extending 187 approximately $20.8 \mathrm{~mm}$ by $16.4 \mathrm{~mm}$ above the surface of the target container. The ratio was 188 selected so as to ensure that a marker would always be visible along the field of view and that the 189 projectile trajectory would be captured, even if there was a deviation of the projectile flight from 190 the vertical trajectory following impact. Following each test, the acquired images were analyzed 191 by counting the inter frame integer pixel displacement of the projectile, over the entire 192 penetration event, or for the duration for which the projectile and the attached rod were visible in 193 the field of view. The recorded integer displacements were then assembled into penetration time 194 histories, by means of conversion of displacements from image coordinates to physical 195 coordinates.

196 The visual record of each penetration event was analyzed by three independent observers to 197 obtain three displacement time histories. Tests were accepted when two of the displacement time 198 histories matched one another ( $\pm 2 \mathrm{~mm}$ terminal penetration depth), otherwise the test was 199 repeated. Tests were not averaged in order to maintain the high frequency component of the 200 record, thus one of the matching tests was selected for further analysis.

201 A feature of the above procedure was that the position of the penetrator with respect to the 202 surface of the target was not precisely known. Penetration time histories therefore needed to be 203 analyzed to ensure the point of impact was correctly identified for plotting and comparison 204 purposes. Velocity time histories included pre-impact and post impact data. Since velocity decay 205 following impact resulted in a change in the slope of the velocity time history, the two distinct 
sections of the velocity time history were examined to determine the point of impact. First, a straight line was fit to approximately $0.2-0.3 \mathrm{~ms}$ of the region that constituted the post impact portions of smoothed velocity time histories. Second, the pre impact straight line was then extended so that the two lines intersected. Next, a line was constructed to bisect the angle formed by the two lines. The intersection of this line and the velocity time history was determined as the point of impact, as shown in Fig 6a for several representative tests. The error in the impact time determined through the above-described procedure was less than $0.04 \mathrm{~ms}$.

Acceleration time histories were calculated by means of single differentiation of the velocity time histories. Since integer pixel locations were recorded in the penetration time histories, a step-type artifact occurs in the position-time data, which causes high frequency noise in the velocity-time data. The velocity time histories were therefore smoothed using a sliding local polynomial fit. This was performed by means of employing a Savitsky-Golay smoothing algorithm. A fourth order polynomial was fitted to 10-20 points on both ends of each point of the velocity time histories, that is, a 21-point or a 41-point sliding polynomial fit was obtained, depending on the level of noise observed in the time histories. Following the above procedure, smoothed velocity time histories were obtained, from which single differentiation yielded acceleration time histories. A similar smoothing algorithm was then applied to the acceleration time histories, to reduce the noise produced by differentiation.

The procedure was highly repeatable; for example repeatability and scatter of velocity-time record is investigated in Fig $6 \mathrm{~b}$ for 3 representative tests, with standard error shown at ten point intervals. The figure shows that the tests had a maximum standard error of 0.015 . Therefore, only representative test results are shown for each test in subsequent figures, to preserve clarity of presentation.

\section{Test results}

\subsection{Results for dry materials}

A total of 80 tests were performed as part of this study. The variables probed, along with the range of each variable as well as details of the test matrix are shown in Table 1. Penetration-time histories and corresponding velocity-time histories for penetration into various loose and densely packed dry granular media using hemispherical-nose rods are shown in Fig 7. Penetration-time histories are shown from the time of impact to that of the terminal penetration depth in the case of 

densely packed media. For loosely packed targets the follower was not visible in the field of view once the penetrator had slowed to velocities of $15-35 \mathrm{~m} / \mathrm{s}$, depending on the target material.

It can be seen from the penetration vs time plots that results are somewhat material dependent. For loose packing, the two silica-based materials are very similar, as are the two carbonaceous materials. The calcareous material is more difficult to penetrate. For densely packed materials, each target medium has a distinct penetration curve. Silica sand is still the easiest material to penetrate. Calcareous aragonite sand is the most difficult. The fused quartz and crushed coral are intermediate. Considering the different range of specific gravities of the various materials tested, these penetration curves suggest that density is not the sole factor determining penetration dynamics, and particle shape and strength characteristics may also play a role.

There are consistent trends in the velocity-time data. There appears to be two penetration regimes in the loosely packed media and three in the case of densely packed media. For both packing conditions, there is an initial steep drop in velocity associated with impact and embedment of the projectile, followed by a second stage in which the deceleration $(\mathrm{d} v / \mathrm{d} t)$ is nearly constant, and, in the dense material, a final regime towards the terminal penetration depth, where the deceleration increases just before the projectile comes to rest. Evidence of the existence of different penetration regimes can be seen from tests reported by Thompson (1975) as well. Existence of these contrasting regimes may point to underlying change in penetration resistance mechanisms.

Velocity data was differentiated to obtain the acceleration-time histories (Fig. 7). Several features can be identified: (1) there is an initial peak deceleration in all traces, associated with impact and embedment. Embedment time for all traces are similar, with a duration on the order of $D / v_{0}$, the time required for the first diameter penetration, where $D$ is the projectile diameter and $v_{0}$ is the impact velocity. The peak deceleration in this transient depends strongly on the material. Its value is proportional to density. (2) Following embedment deceleration drops sharply, and depends only slightly on material. It is greatest for the densely packed materials. (3) After about 1-1.5 ms, the deceleration reaches a plateau at a relatively low value where it is nearly constant. (4) There are quasi-periodic oscillations in the acceleration records. Amplitudes of these oscillations are higher in loose materials. These oscillations are not artifacts of the pixilation of displacement, and there is evidence in the literature that they correspond to formation and buckling of force chains during penetration (e.g., Clark et al. 2014).

\subsection{Role of nose shape}


The effect of nose shape was investigated by penetrating dense Ottawa sand and Aragonite targets using long rods with three different nose shapes, namely, hemispherical, conical and blunt. The comparisons are shown in Figs 8 and 9. It can be seen that the nose shape has a much more significant effect in Ottawa sand compared to aragonite sand. Nose shape has a noticeable effect in the case of dense Ottawa sand, where the conical nose has the largest penetration depth, followed by hemispherical and blunt nose shapes.

Contrary to Ottawa sand, nose shape has a less significant effect in the case of penetration into dense aragonite sand. It can be seen in Fig 9 that blunt and hemispherical nose shapes produce nearly identical penetration depths, while the conical nose shaped projectile only marginally increases penetration depth. Since both materials have rounded particles, and the main difference between the two is the higher susceptibility of aragonite sand to crushing compared to Ottawa sand, it can be postulated that the difference in the nose shape dependence of the two materials may be related to particle crushing during penetration.

There is evidence in the literature that when projectiles penetrate granular media at high enough penetration velocities to induce particle damage, crushed particles form a dense region immediately ahead of the projectile (e.g., Tanaka 2011; Kotov et al. 2013). This region of compacted crushed materials forms a conical shape, and may behave as a 'false cone', effectively reshaping the projectile nose during penetration. Post-mortem inspection of the penetration front in aragonite samples confirmed the formation of a false cone in high velocity sphere penetration tests, as evidenced in Fig 10. Preliminary analysis of the cone revealed that it exhibited a bimodal size distribution, with materials either relatively intact, or comminuted to micron-size particles. It is hypothesized that the formation of a false cone reduces the nose shape effect. In the case of Ottawa sand, nose shape affects momentum transfer, as particles have to gain momentum to move out of the trajectory of the penetrator. However, in the case of aragonite sand, the false nose formed by the crushed particles gives penetrators with different nose shapes an effectively conical nose shape during penetration.

\subsection{Effect of water saturation}

The effect of saturation was studied by performing penetration tests using the hemispherical projectile in wet samples. At the strain rates experienced during penetration all the target materials are expected to behave undrained in the vicinity of penetration (Omidvar et al. 2014). Comparison of penetration tests at impact velocities in the range of $80 \pm 5 \mathrm{~m} / \mathrm{s}$ is shown in Fig 11 for loosely packed and densely packed Ottawa sand, aragonite and crushed coral targets. Despite 
299 having similar relative densities (relative to minimum and maxim densities), the material possess

300 different void ratios (defined as the ratio of volume of voids to volume of solids), as listed in

301 Table 1. It can be seen from the results that penetration into dry and wet targets produce 302 contrasting response.

303 For all loosely packed materials, saturation clearly decreases penetration, although the effect on 304 final penetration depth cannot be quantified because for the dry condition, there was total 305 embedment of the projectile and its follower in the target. For densely packed materials the 306 terminal penetration depth decreased by approximately $67 \%$ and $5 \%$ for dense Ottawa sand and 307 crushed coral targets, respectively due to saturation. Accordingly, there is little effect in the 308 calcareous sand, while significant reduction in penetration depth can be seen in Ottawa sand. For 309 dense materials, the main effect of saturation was manifested in the second velocity regime, 310 where deceleration is significantly higher in the wet sample. The result is that the velocity-time 311 history and velocity-penetration curves of the loosely-packed wet target resembles that of the 312 dense dry target. In particular, in the case of Ottawa sand, saturation appears to suppress the 313 change in the slope of the velocity-time history, which occurs at approximately $0.55 \mathrm{~V}_{0}$ in the dry 314 target (Figure 11). The result is that there is a significant decrease in penetration depth in the wet 315 target, owing almost entirely to the aforementioned contrasting response below approximately $3160.55 \mathrm{~V}_{0}$. In contrast, saturation has nearly no effect on penetration into dense crushed coral. This 317 may be because penetration into dense Ottawa sand is accommodated by movement of particles 318 away from the trajectory of the projectile, whereas penetration into dense crushed coral is 319 facilitated mainly by crushing of particles. The effect of saturation is therefore to restrict particle 320 motion in dense Ottawa sand, while in crushed coral the pore fluid does not significantly affect 321 particle crushing.

322 It is noteworthy that while the large difference in penetration depth due to saturation in Ottawa 323 sand and crushed coral are due to intrinsic behavior, the actual values are to a small degree 324 affected by the variation in impact velocity between the tests, which is up to $6 \mathrm{~m} / \mathrm{s}$ in all tests 325 except in loose aragonite, where the difference is more significant, at approximately $20 \mathrm{~m} / \mathrm{s}$.

\section{3.4. Penetration of Spheres at High Velocity}

327 Penetration time histories for spheres at impact velocities in the range of $150-300 \mathrm{~m} / \mathrm{s}$ were 328 obtained by means of the PDV described in Section 2.4. PDV measurements provide higher 329 temporal resolution for small changes in velocity. 
Results of penetration tests into dry Ottawa sand and crushed fused quartz are shown in Fig 12. Several features can be identified from these plots. First, it can be seen that at high velocities, packing density does not significantly affect penetration into fused quartz, whereas it has a marked effect on penetration into Ottawa sand. Moreover, it can be seen that a transition regime exists in the velocity time histories of Ottawa sand at $60-80 \mathrm{~m} / \mathrm{s}$ penetration velocity. This transition regime is more evident in dense Ottawa sand compared to loose Ottawa sand. However, the transition is not discernable in the case of crushed fused quartz. The difference between the two materials can also be seen in the deceleration plots of Fig 12c, where regions with different slopes can be identified in the Ottawa sand curves, whereas both loose and dense crushed fused quartz show similar, relatively monotonic deceleration throughout the measurement.

The effect of saturation was investigated for Ottawa sand. Penetration and velocity time histories are shown in Fig 13. It can be seen that in the wet tests the PDV signal was lost earlier in the penetration compared to dry tests, as a result of ejecta obscuring the path of the laser light source. Comparison of the dry and wet time histories reveals that contrary to the lower velocity tests, resistance to penetration at high velocities is lower in wet samples compared to dry samples. The effect of saturation is more significant in the case of loose sand. For example, at approximately $0.5 V_{0}$, penetration in loose wet sand is approximately $77 \%$ greater in the case of wet sand compared to dry sand, whereas in dense sand the increase in depth due to saturation is approximately $35 \%$.

The data portray the somewhat surprising result that the effect of saturation varies greatly with velocity. For dense sand especially, in the range of 300 to about $60 \mathrm{~m} / \mathrm{s}$, saturation decreases penetration resistance, but the opposite is true at lower velocities. It is believed that projectile penetration gives rise to a number of related complex effects including (1) changes of porosity ahead of the projectile (positive or negative depending on initial packing); (2) increase in pore water pressure, may lead to loss of stiffness and strength which can reach a limit state known as liquefaction, depending on porosity and provided the degree of saturation is sufficiently high; and (3) particle fracture or comminution which contribute to changes in porosity and may also affect the rate of dissipation of pore pressures due to plugging of pore space. Although the data is not yet conclusive, one possible explanation of this effect is that dynamic shear dilatancy is resisted by pore water. Since shear strength comes to dominate penetration resistance as velocity falls, a wet material appears to be harder to penetrate than a dry one. There could be at least two meso scale processes involved: the viscosity of the water suppresses relative movement of particles, and pore creation is difficult because water resists dilation. Another hypothesis is that at high 
velocity water may suppress stress gradients within grains, thereby reducing fracture, but this effect is less important at low speeds where fracture does not occur even in dry material. Eventually, as penetration becomes quasi static, the influence of pore water likely diminishes.

\section{Discussion}

\subsection{Phenomenology}

Phenomenological models provide a framework for approaching penetration mechanics, in which penetration is a function of assumed forces with non-dimensional fitting coefficients. Newton's third law of motion implies that the force exerted by the penetrator on the target equals the force exerted by the target on the penetrator. Force is obtained from Newton's second law of motion. The resistance to penetration offered by the target, $F$, is expanded into a polynomial with various orders of dependence on velocity. The general form of the equation can be written as:

$$
m_{p} \frac{d v}{d t}=F=m_{p} g-\alpha v^{2}-\beta v-\gamma
$$

where $m_{p}$ is the projectile mass, $v$ is instantaneous projectile velocity at a given time $t, \mathrm{~g}$ is gravitational acceleration, $\gamma$ is a parameter (with units of force) dominated by the bearing strength of the soil; $\beta$ controls the contribution of viscous resistance of soil (with units of mass over time); and $\alpha$ represents the contribution of inertial stresses (with units of mass over length). The terms in Eq 3 were individually investigated for their ability to describe the data. In initial fits it was found that the viscous component had a negligible role in improving fits to the data, and only the inertial and frictional terms were considered in the analyses. First a velocity range was identified that was well fit by the quadratic velocity term. Next, a residual force was calculated as the difference between dynamic resistance and the inertial fit to the entire time history of the data. The residual force was then used to evaluate the role of frictional resistance. In order to do so, quasi static penetration tests were performed, and the residual force was compared to the quasi static penetration resistance.

The inertial component of resistance to penetration can be expressed as a quadratic drag force by employing momentum transfer and Newton's third law. Accordingly, an object having a cross sectional area $A$ advancing at a velocity $v$ in an incompressible fluid over a time period $\mathrm{d} t$, encounters an increment of mass, $\mathrm{d} m_{g}=\rho_{g} A v \mathrm{~d} t$. This material is either moved aside or pushed forward, but in either event acquires a velocity proportional to $v$. Therefore, a momentum proportional to $\mathrm{d} p=\mathrm{vd} m_{g}=\rho_{g} A v^{2} \mathrm{~d} t$ is imparted to the medium. According to Saslow and $\mathrm{Lu}$ 
393 (2008), Newton derived this relationship, and noted that the above momentum transfer is doubled 394 by virtue of perfect reflection for a flat projectile. In practice, a new empirical parameter, $C_{D}$, 395 referred to as the drag coefficient is introduced to the equation, which is often assumed to be 396 independent of penetration velocity. The common convention in fluid dynamics is to adopt $1 / 2 C_{D}$ 397 in the momentum equation. The force $F$ in Eq 3 is therefore obtained as $F=-\mathrm{d} p / \mathrm{d} t$, resulting in the 398 following relationship:

$$
F=-1 / 2 C_{D} \rho_{g} v^{2} A
$$

400 In order to evaluate the efficacy of Eq 4 in describing penetration dynamics, the acceleration time 401 histories shown in Fig 7 were normalized by the dynamic stress by dividing $m a / A$ by $\rho_{g} v^{2}$. The 402 resulting non-dimensional term was fitted with a constant, as shown in Fig 14 (dashed lines). 403 Comparing the normalized term and Eq. 4 reveals that the average constant value corresponds to $4041 / 2 C_{D}$. For both loose and dense targets a reasonable fit using a constant drag coefficient can be 405 found for velocities down to approximately $20-30 \mathrm{~m} / \mathrm{s}$. The values of the drag coefficient 406 obtained by the above described method are listed in Table 2. Drag coefficients were in the range 407 of $0.92-1.27$ for loosely packed media and 1.86-2.26 for densely packed media.

408 A significant finding was that for a given relative density, the drag coefficient was only moderately influenced by the material (Table 2). However, the drag coefficient does depend upon bulk density. For dense materials, the resistance to penetration apparently involves more than simple momentum transfer to the target grains in the path of the projectile. Comparison of drag coefficients obtained from loose and dense targets is also shown in Table 2. The data from the high impact velocity tests using spheres into Ottawa sand are consistent with the data from hemispherical rod tests at similar penetration velocities. Based on the data from high velocity and low velocity tests, two transition regimes can be identified in the velocity time histories (Fig. 15). The first occurs at penetration velocities in the range of $60-80 \mathrm{~m} / \mathrm{s}$, and the second transition occurs at approximately $15-20 \mathrm{~m} / \mathrm{s}$. The observation persists for other materials in dense states, where data is available for all HSI measurements but for the high-speed measurements laser reflection from the projectile was interrupted, which prevented capturing data in PDV measurements. These two transition regimes may point to change in the mechanism of resistance to penetration, as discussed in the next sections.

\subsection{High velocity transition}


It appears that there is a transition regime in penetration resistance, occurring at approximately $60-80 \mathrm{~m} / \mathrm{s}$. There is a distinct change in the slope of the velocity time history over these velocities, which could be due to a change in the energy transfer mechanism. The transition zones are more pronounced in the case of densely packed targets, and are more evident in Ottawa sand compared to fused quartz. Previous studies have found that these penetration velocities also correspond to the velocity range above which particle damage is significant, and below which there is a marked reduction in the damage to particles during penetration. For example, Bless et al. (2009) and Cooper and Breaux (2010) have reported a trail of comminuted sand along the trajectory of the projectile at velocities greater than those associated with this transition regime, and diminishing trails of comminuted sand at lower velocities (Fig. 16). Preliminary inspection of the crushed material It is believed that the observed transition in penetration resistance is associated with the threshold of significant particle damage.

\subsection{Low velocity transition}

The sharp increase observed in drag at lower velocities is analogous to behavior of objects moving through fluids. At high Reynolds numbers (high velocities), resistance to penetration in fluids is also proportional to velocity squared, and drag coefficient is constant. At low velocities, viscosity dominates and resistance is proportional to velocity to the first power, and drag coefficient increases rapidly. The transition between the inertial and viscous regimes is determined by the Reynolds number, that is, the ratio of inertial to viscous forces. It was found that resistance passes from a $v^{2}$ dependence to one dominated by a $v^{0}$ dependence. In these circumstances, the transition between behavior regimes is controlled by the so-called solid Reynolds number (Bernard and Hanagud 1975; Yankelevsky and Gluck 1980), which can be written as follows

$$
\operatorname{Re}_{S}=\frac{\rho v^{2}}{\tau}
$$

where $\tau$ is the quasi static resistance to penetration. In order to investigate this transition, quasi static penetration tests were performed into dry targets under dense packing. The tests were performed by penetrating a long rod with a hemispherical nose and a diameter matching that of the projectiles into the targets. A hydraulic actuator was used to penetrate the rod into the targets at a penetration rate of $0.05 \mathrm{~mm} / \mathrm{s}$. Penetration resistance was measured by means of a load cell attached to the end of the long rod. Results of the measurements are shown in Fig (17) for penetration into dense aragonite sand. The residual dynamic force calculated as the difference 
454 between the measured dynamic resistance to penetration (calculated from the acceleration record)

455 and the quadratic fit to the same data using Eq. 4. is also shown in the figure.

456 Inspection of the dynamic and quasi static penetration resistance reveals that (1) during the initial 457 portion of penetration corresponding to impact and partial embedment, dynamic resistance is up 458 to two orders of magnitude larger than quasi static penetration resistance. (2) As dynamic 459 penetration depth increases, dynamic resistance reduces to values of the same order as that of the 460 quasi static resistance. At approximately 5D penetration, the two values match. (3) Beyond this 461 penetration depth, the residual dynamic resistance matches to a reasonable extent to the quasi 462 static resistance, as shown in the inset. The match between the two values can be further 463 improved by shifting the quasi static penetration resistance to the left of the penetration axis by 464 approximately 3D, as shown in Fig 17, and the inset of the figure. This shift is simply a 465 convenient means to account for the greater volume of soil involved in frictional resistance to 466 dynamic penetration relative to static penetration as suggested by Collins et al. (2011). This 467 match suggests that the term $\gamma$ in Eq (3) can be derived from quasi static penetration resistance. 468 Moreover, the depth dependent, nonlinear increase in the quasi static penetration resistance 469 suggests that $\gamma$ is depth dependent, and the $\gamma(z)$ can be reasonably derived from standard 470 penetrometer tests in soils.

471 The term $\gamma$ in Eq. 3 is material dependent, as shown in Fig 18, and there is a significant difference 472 between the different materials. For example, at 10D penetration depth, quasi static resistance of 473 fused quartz and aragonite differ by as much as $500 \%$. For the materials tested, Aragonite has the 474 largest quasi static resistance, followed by crushed coral, Ottawa sand, and fused quartz. This 475 strong material dependence points to the importance of frictional response in the penetration 476 dynamics, particularly at lower velocities.

\section{5. Conclusions}

478 Data for penetration resistance of four different granular media including Ottawa sand, crushed 479 coral, aragonite, and crushed fused quartz has been assembled. The parameter space included two 480 packing densities of loosely packed and densely packed targets, four different projectiles 481 including spheres and long rods with conical, hemispherical and blunt nose shapes, and two pore 482 fluid conditions of dry and wet media. Impact velocities in the range of 65 to $300 \mathrm{~m} / \mathrm{s}$ were considered. Several observations were reported from the penetration tests, as follows: 

Effect of packing density: Increasing the packing density generally reduced penetration depth, and increased deceleration of the projectile. Moreover, there appeared to be two transition regimes in penetration into densely packed targets, where a discernable change in deceleration could be identified in dense soils.

Effect of saturation: The role of saturation was found to be material dependent. In silica sand, saturation generally reduced penetration depth in tests performed at impact velocities below 100 $\mathrm{m} / \mathrm{s}$. The reduction was greater in densely packed targets compared to loosely packed targets. In calcareous targets, saturation reduced penetration depth in loose targets but had negligible effect on penetration into dense targets.

Effect of projectile nose shape: The role of nose shape was also material dependent. In Ottawa sand, conical projectiles penetrated deeper than hemispherical nose rods, followed by blunt nose projectiles. However, in calcareous sand, the penetrator nose shape had negligible effect on penetration. The role of particle crushing and the apparent 'false cone' was suggested as the justification for this contrasting behavior in silica and calcareous sands.

\section{Acknowledgements}

The authors gratefully acknowledge the support of the Defense Threat Reduction Agency (DTRA) of the United States of America, Grant No: HDTRA1-10-1-0049. High-speed imaging was carried out by a NAC HX5 camera. HSI data were collected by Felipe Magleau Martins and Gustavo Souza Loureiro Lima, sponsored by the Brazil Scientific Mobility Program and Swaroop Shankar.

\section{References}

ASTM D2487-11. 2011. Standard Practice for Classification of Soils for Engineering Purposes (Unified Soil Classification System). Annual Book of ASTM standards, ASTM International, West Conshohocken, PA.

ASTM D4253. 2006. Standard Test Methods for Maximum Index Density and Unit Weight of Soils Using a Vibratory Table. Annual Book of ASTM standards, ASTM International, West Conshohocken, PA.

ASTM D4254. 2006. Standard test methods for minimum index density and unit weight of soils and calculation of relative density. Annual Book of ASTM standards, ASTM International, West Conshohocken, PA.

ASTM D854-14. 2014. Standard test methods for specific gravity of soil solids by water 
pycnometer. Annual Book of ASTM standards, ASTM International, West Conshohocken, PA.

Bernard RS, Hanagud SV. Development of a Projectile Penetration Theory: report 1, penetration theory for shallow to moderated depths. Technical report S-75-9. Vicksburg, MS: US Engineer Waterways Experiment Station; 1975. p. 66.

Bless SJ, Berry DT, Pederson B, Lawhorn W. Sand penetration by high speed projectiles. In: Elert ML, Furnish MD, Anderson WW, Proud WG, Butler WT, editors. Proceedings of shock compression of condensed matter. Nashville, TN: American Institute of Physics; 2009. pp. 1361-4.

Cave A, Roslyakov S, Iskander M, Bless, S. Design and performance of a laboratory pneumatic gun for soil ballistic applications. Experimental Techniques 2014; doi:10.1111/ext.12091.

Clark AH, Peterson AJ, Behringer RP. Collisional model for granular impact dynamics. Physical Review E 2014; 89(1,2):012201.

Collins AL, Addiss JW, Walley SM, Promratana K, Bobaru F, Proud WG, Williamson DM. The effect of nose shape on the internal flow fields during ballistic penetration of sand. International Journal of Impact Engineering 2011;38:951e63.

Cooper WL, Breaux BA. Grain fracture in rapid particulate media deformation and a particulate media research roadmap from the PMEE workshops. International Journal of Fracture 2010;162:137-50.

Kotov VL, Balandin VV, Bragov AM, Balandin VV. Quasi-steady motion of a solid in a loose soil with developed cavitation. Doklady Physics 2013; 58(7):309-313.

Omidvar M, Iskander M, Bless S. Response of granular media to rapid penetration. International Journal of Impact Engineering 2014; 66:60-82.

Omidvar M, Iskander M, Bless S. Stress-strain behavior of sand at high strain rates. International Journal of Impact Engineering 2012; 49:192-213.

Peden R, Omidvar M, Bless S, Iskander M. Photonic Doppler velocimetry for study of rapid penetration into sand. Geotechnical Testing Journal 2014; 37(1): 139-150.

Rad NS, Tumay MT. Factors affecting sand specimen preparation by raining. Geotechnical Testing Journal 1987; 10(1):31-7.

Saslow WM, Lu H. Newton on objects moving in a fluid - the penetration length. European Journal of Physics 2008;29:689-96.

Tanaka K. Phenomenological studies of the response of granular and geological media to highspeed projectiles. Report no. AOARD-104115. Asian Office of Aerospace Research and 
Development; 2011. p. 14.

Thompson JB. Low-velocity impact penetration of low-cohesion soil deposits [Ph.D. dissertation]. Berkeley, CA: University of California; 1975.

Yankelevsky DZ, Gluck J. Nose shape effect on high velocity soil penetration. International Journal of Mechanical Sciences 1980; 22:297-311.

Table 1: Matrix of penetration tests performed

\begin{tabular}{|c|c|c|c|c|c|c|c|c|}
\hline Soil Type & $\begin{array}{l}\text { Relative } \\
\text { Packing }\end{array}$ & Projectile & Saturation & Test ID & $\begin{array}{c}\text { Impact } \\
\text { Velocity } \\
(\mathrm{m} / \mathrm{s})\end{array}$ & $\begin{array}{c}\text { Target } \\
\text { Dry Density } \\
\left(\mathrm{g} / \mathrm{cm}^{3}\right)\end{array}$ & $\begin{array}{c}\text { Void } \\
\text { Ratio* }\end{array}$ & $\begin{array}{c}\text { \# of } \\
\text { repeats }\end{array}$ \\
\hline \multirow{12}{*}{ Ottawa Sand } & \multirow{6}{*}{$\begin{array}{l}\text { Loosely } \\
\text { Packed }\end{array}$} & \multirow{2}{*}{ Sphere } & Dry & OS-LP-S-D & 297.4 & 1.587 & 0.67 & 1 \\
\hline & & & Wet & OS-LP-S-W & 303.0 & 1.600 & 0.66 & 1 \\
\hline & & \multirow{2}{*}{$\begin{array}{l}\text { Hemispherical } \\
\text { Rod }\end{array}$} & Dry & OS-LP-HR-D & 83.9 & 1.670 & 0.59 & 4 \\
\hline & & & Wet & OS-LP-HR-W & 77.3 & 1.660 & 0.60 & 4 \\
\hline & & Blunt Rod & Dry & OS-LP-BR-D & 74.1 & 1.640 & 0.62 & 2 \\
\hline & & Conical Rod & Dry & OS-LP-CR-D & 76.8 & 1.680 & 0.58 & 1 \\
\hline & \multirow{6}{*}{$\begin{array}{l}\text { Densely } \\
\text { Packed }\end{array}$} & \multirow{2}{*}{ Sphere } & Dry & OS-DP-S-D & 299.2 & 1.817 & 0.46 & 1 \\
\hline & & & Wet & OS-DP-S-W & 302.5 & 1.819 & 0.46 & 3 \\
\hline & & \multirow{2}{*}{$\begin{array}{c}\text { Hemispherical } \\
\text { Rod }\end{array}$} & Dry & OS-DP-HR-D & 79.7 & 1.830 & 0.45 & 4 \\
\hline & & & Wet & OS-DP-HR-W & 73.9 & 1.830 & 0.45 & 1 \\
\hline & & Conical Rod & Dry & OS-DP-CR-D & 72.8 & 1.832 & 0.45 & 1 \\
\hline & & Blunt Rod & Dry & OS-DP-BR-D & 78.3 & 1.820 & 0.46 & 1 \\
\hline \multirow{4}{*}{ Fused Quartz } & \multirow[b]{2}{*}{$\begin{array}{l}\text { Loosely } \\
\text { Packed }\end{array}$} & Sphere & Dry & FQ-LP-S-D & 303.0 & 1.187 & 0.85 & 2 \\
\hline & & $\begin{array}{c}\text { Hemispherical } \\
\text { Rod }\end{array}$ & Dry & FQ-LP-HR-D & 83.7 & 1.030 & 1.14 & 3 \\
\hline & \multirow[b]{2}{*}{$\begin{array}{l}\text { Densely } \\
\text { Packed }\end{array}$} & Sphere & Dry & FQ-DP-S-D & 302.5 & 1.298 & 0.69 & 1 \\
\hline & & $\begin{array}{l}\text { Hemispherical } \\
\text { Rod }\end{array}$ & Dry & FQ-DP-HR-D & 71.2 & 1.170 & 0.88 & 4 \\
\hline \multirow{4}{*}{ Crushed Coral } & Loosely & \multirow{4}{*}{$\begin{array}{c}\text { Hemispherical } \\
\text { Rod }\end{array}$} & Dry & CC-LP-HR-D & 77.1 & 1.460 & 0.82 & 1 \\
\hline & Packed & & Wet & CC-LP-HR-W & 70.1 & 1.460 & 0.82 & 1 \\
\hline & Densely & & Dry & CC-DP-HR-D & 76.2 & 1.640 & 0.62 & 3 \\
\hline & Packed & & Wet & CC-DP-HR-W & 80.1 & 1.630 & 0.63 & 1 \\
\hline \multirow{8}{*}{ Aragonite } & \multirow{4}{*}{$\begin{array}{l}\text { Loosely } \\
\text { Packed }\end{array}$} & \multirow{2}{*}{$\begin{array}{c}\text { Hemispherical } \\
\text { Rod }\end{array}$} & Dry & CA-LP-HR-D & 82.0 & 1.600 & 0.71 & 1 \\
\hline & & & Wet & CA-LP-HR-W & 60.2 & 1.580 & 0.73 & 2 \\
\hline & & Blunt Rod & Dry & CA-LP-BR-D & 67.0 & 1.610 & 0.70 & 1 \\
\hline & & Conical Rod & Dry & CA-LP-CR-D & 72.9 & 1.580 & 0.73 & 1 \\
\hline & \multirow{4}{*}{$\begin{array}{l}\text { Densely } \\
\text { Packed }\end{array}$} & \multirow{2}{*}{$\begin{array}{c}\text { Hemispherical } \\
\text { Rod }\end{array}$} & Dry & CA-DP-HR-D & 76.2 & 1.850 & 0.48 & 3 \\
\hline & & & Wet & CA-DP-HR-W & 79.3 & 1.730 & 0.58 & 1 \\
\hline & & Blunt Rod & Dry & CA-DP-BR-D & 78.0 & 1.810 & 0.51 & 1 \\
\hline & & Conical Rod & Dry & CA-DP-CR-D & 77.2 & 1.790 & 0.53 & 2 \\
\hline
\end{tabular}

* ratio of volume of voids to volume of solids

OS: Ottawa sand, FQ: fused quartz, CA: calcareous aragonite, CC: crushed coral, LP: loosely packed, DP: densely packed, HR: hemispherical rod, CR: conical rod, BR: blunt rod, S: spherical projectile, D: dry, W: wet 
Table 2: Drag coefficients calculated from low and high velocity tests

\begin{tabular}{ccccc}
\hline $\begin{array}{c}\text { Target } \\
\text { Parameters }\end{array}$ & $\begin{array}{c}\text { Impact } \\
\text { Velocity (m/s) }\end{array}$ & $\begin{array}{c}\text { Packing } \\
\text { Density } \\
\left(\mathbf{g} / \mathbf{c m}^{\mathbf{3}}\right)\end{array}$ & Void Ratio & $\begin{array}{c}\text { Drag Coefficient from } \\
\left.\text { partial fit (1/2 } \mathbf{C}_{\mathbf{D}}\right)\end{array}$ \\
\hline OS-LP-HR-D & 83.9 & 1.670 & 0.59 & 0.92 \\
\hline OS-DP-HR-D & 79.7 & 1.830 & 0.45 & 1.64 \\
\hline AR-LP-HR-D & 82.0 & 1.600 & 0.71 & 1.21 \\
\hline AR-DP-HR-D & 76.2 & 1.850 & 0.48 & 2.26 \\
\hline CC-LP-HR-D & 77.1 & 1.460 & 0.82 & 1.27 \\
\hline CC-DP-HR-D & 76.2 & 1.640 & 0.62 & 1.22 \\
\hline FQ-LP-HR-D & 83.7 & 1.030 & 1.14 & 2.89 \\
\hline FQ-DP-HR-D & 71.2 & 1.170 & 0.88 & \\
\hline
\end{tabular}




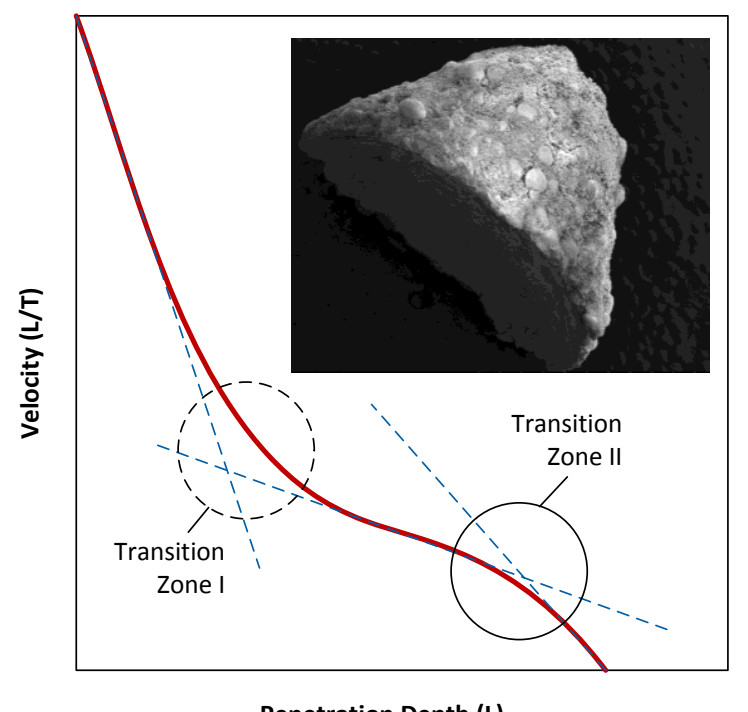

Penetration Depth (L)

Graphicala abstrat

canteratumant

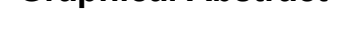

-

作

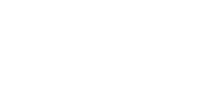


Figure 1

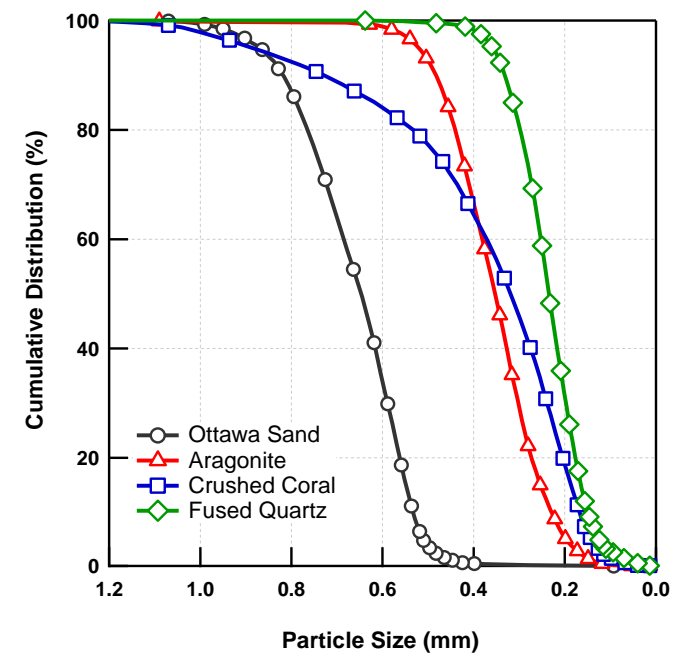

Fig 1: Particle size distribution of four granular media tested 
Figure 2

Typical particle shapes at $d_{50}$
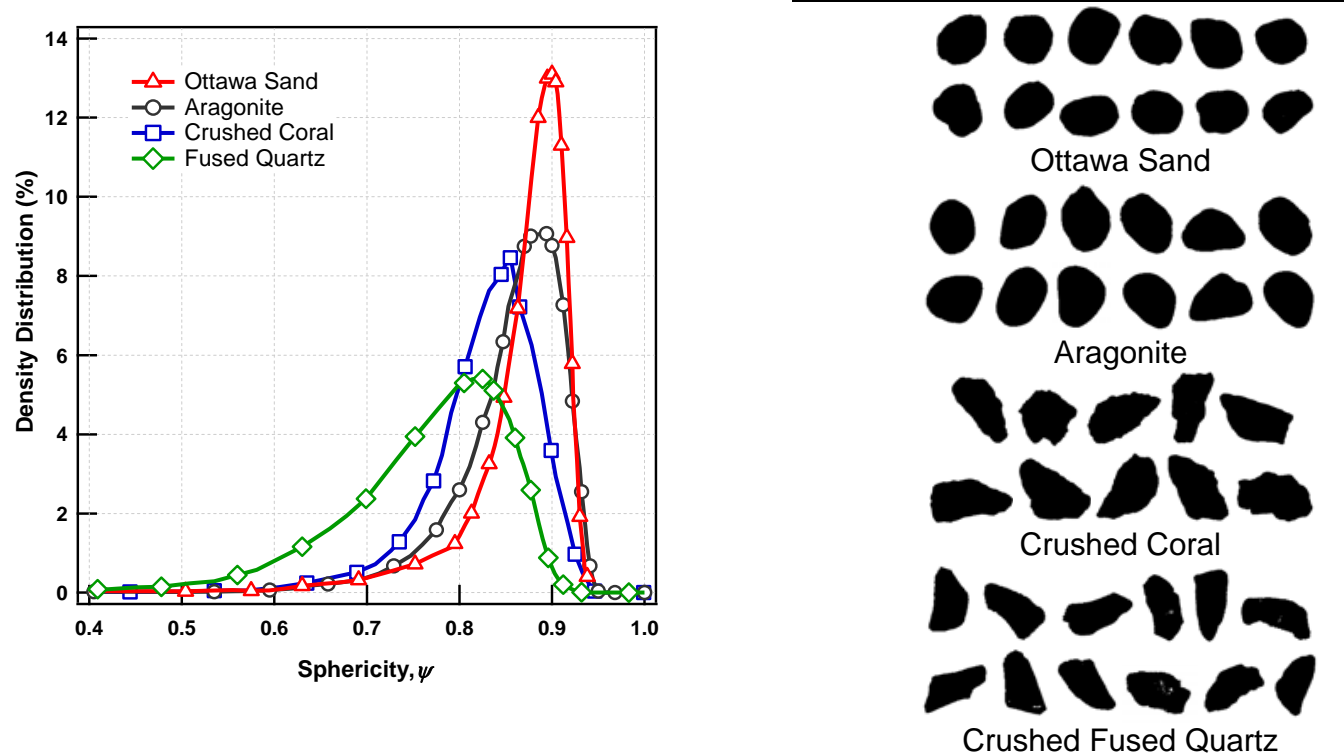

Fig 2: (a) Density distribution of particle sphericity, and (b) Typical two dimensional projections of particle shapes for granular media tested 


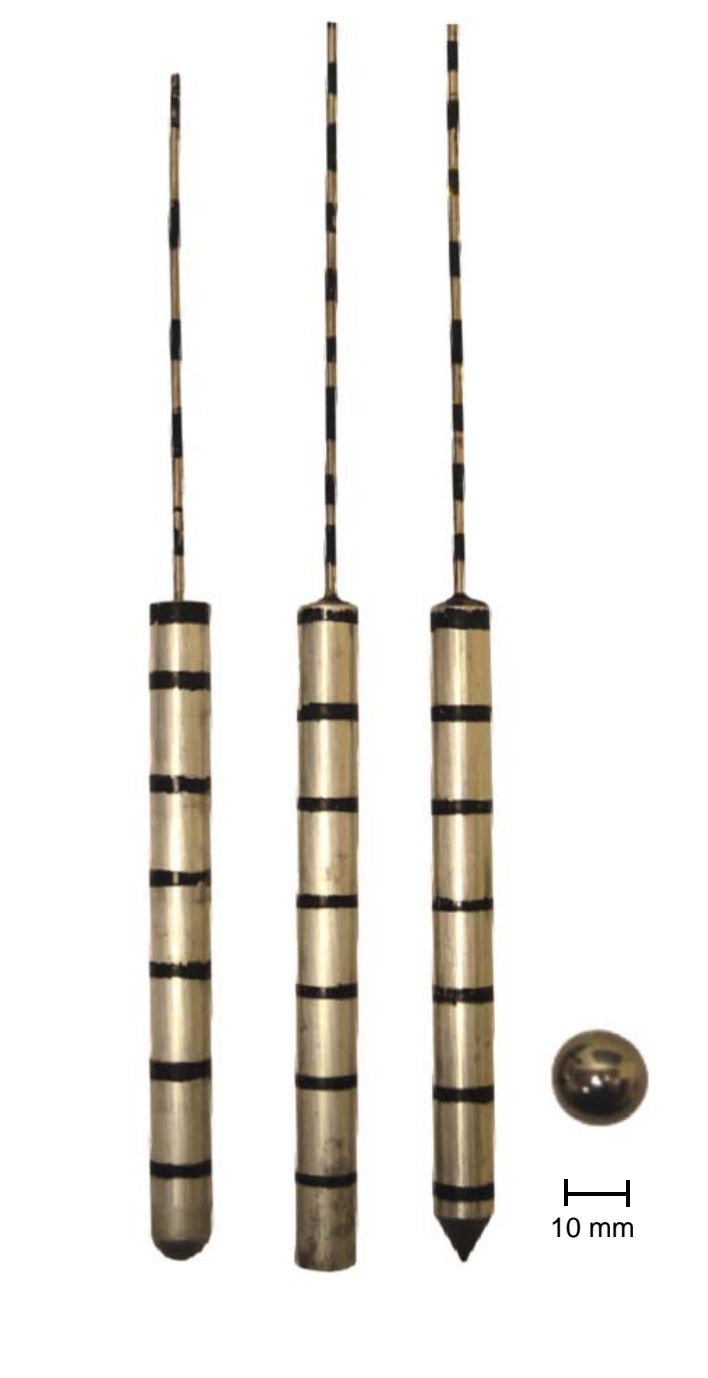

Fig 3: Projectiles used in the penetration tests

Figure 3

Fig 3: Projectiles used in the penetration tests

3

明。

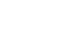

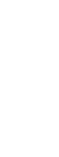

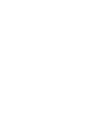

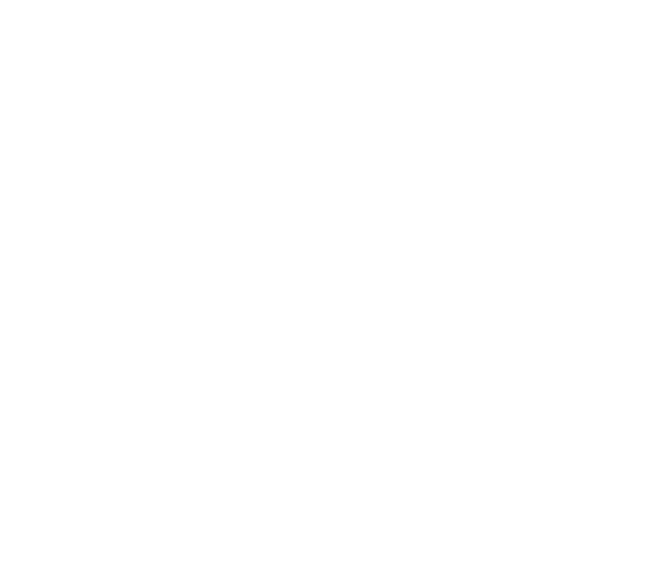


Figure 4

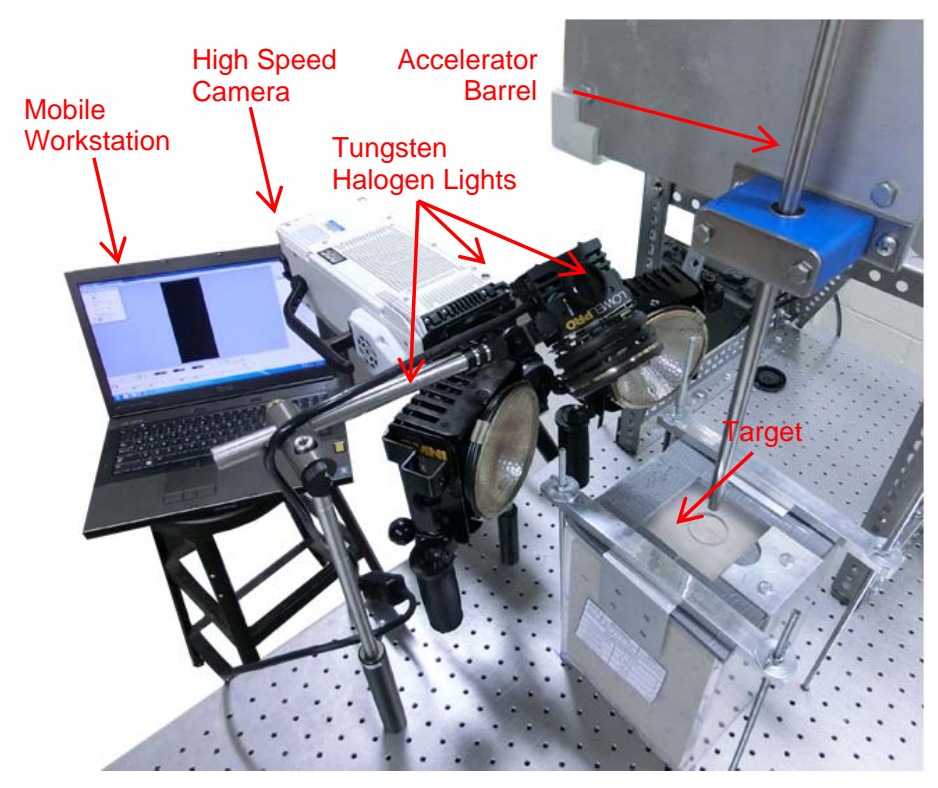

Fig 4: High speed imaging setup used to track projectiles during penetration into granular media 
Figure 5

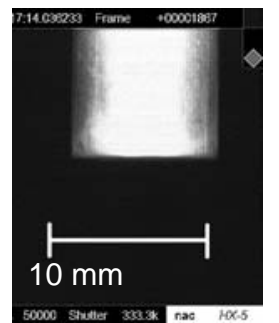

(a)

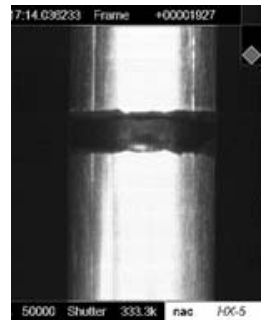

(b)

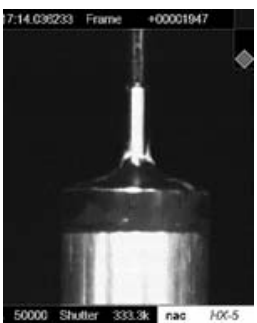

(c)

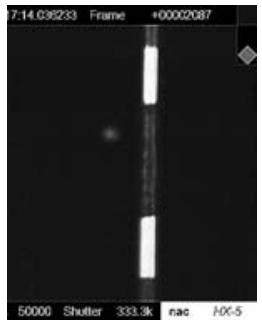

(d)

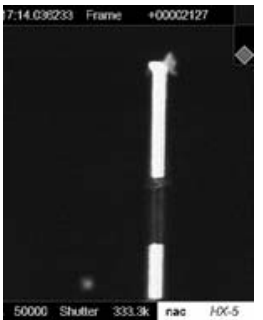

(e)

Fig 5: Snapshots of penetrator passing through the field of view of the camera during HSI of a penetration event $\mathrm{t}=-0.8,0,0.4,3.2$, and $4.0 \mathrm{~ms}$, respectively ( $\mathrm{t}=0 \mathrm{~ms}$ is point of impact) 


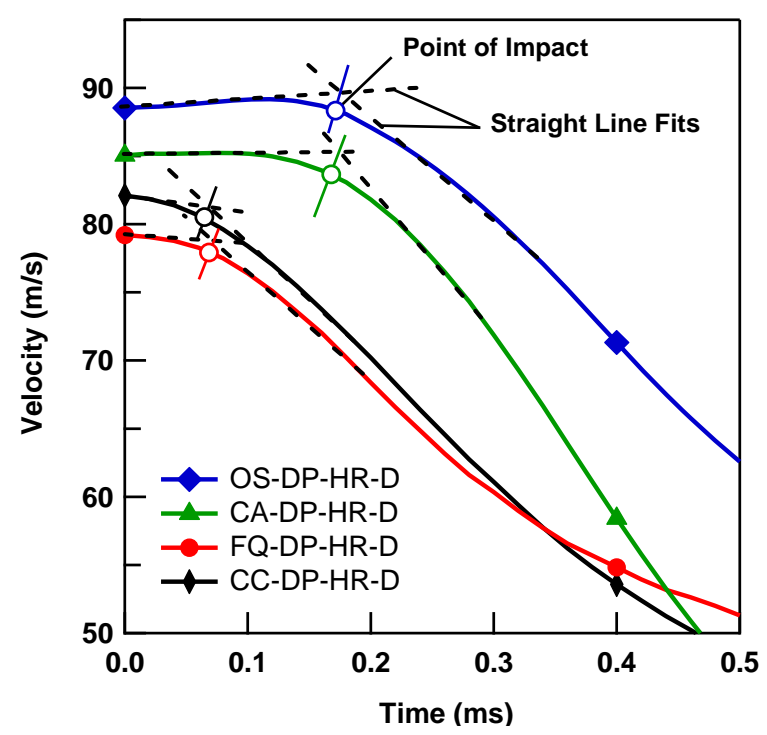

(a)

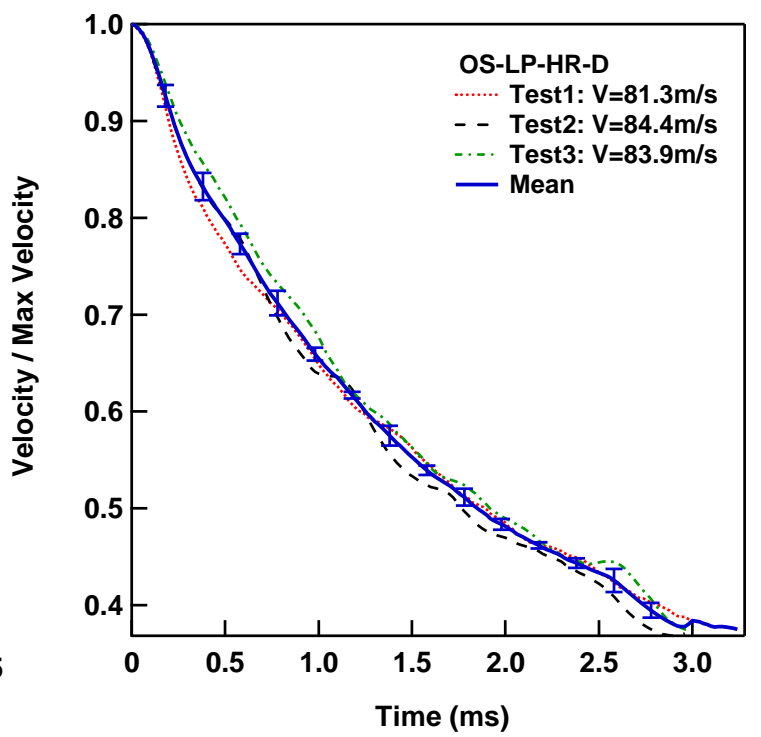

(b)

Fig 6: (a) Procedure used to identify point of impact, and (b) Repeatability of tests performed, shown for penetration into loose and dense dry Ottawa sand using hemispherical rods 

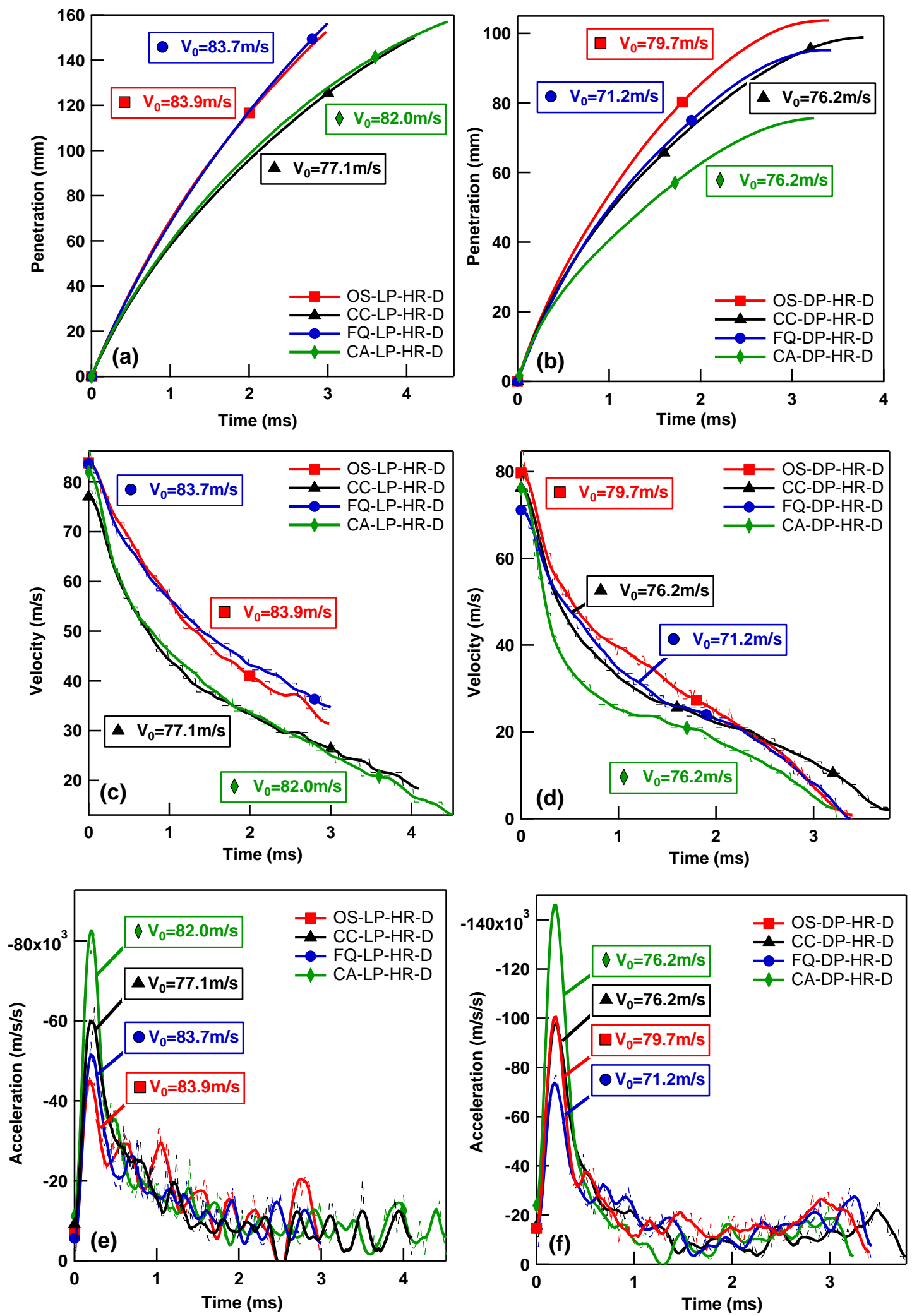

Fig 11: Penetration, velocity, and acceleration time histories for penetration of hemispherical nose rods into loosely packed (a, c, e) and densely packed (b, d, e) granular media (dashed lines represent raw data) 

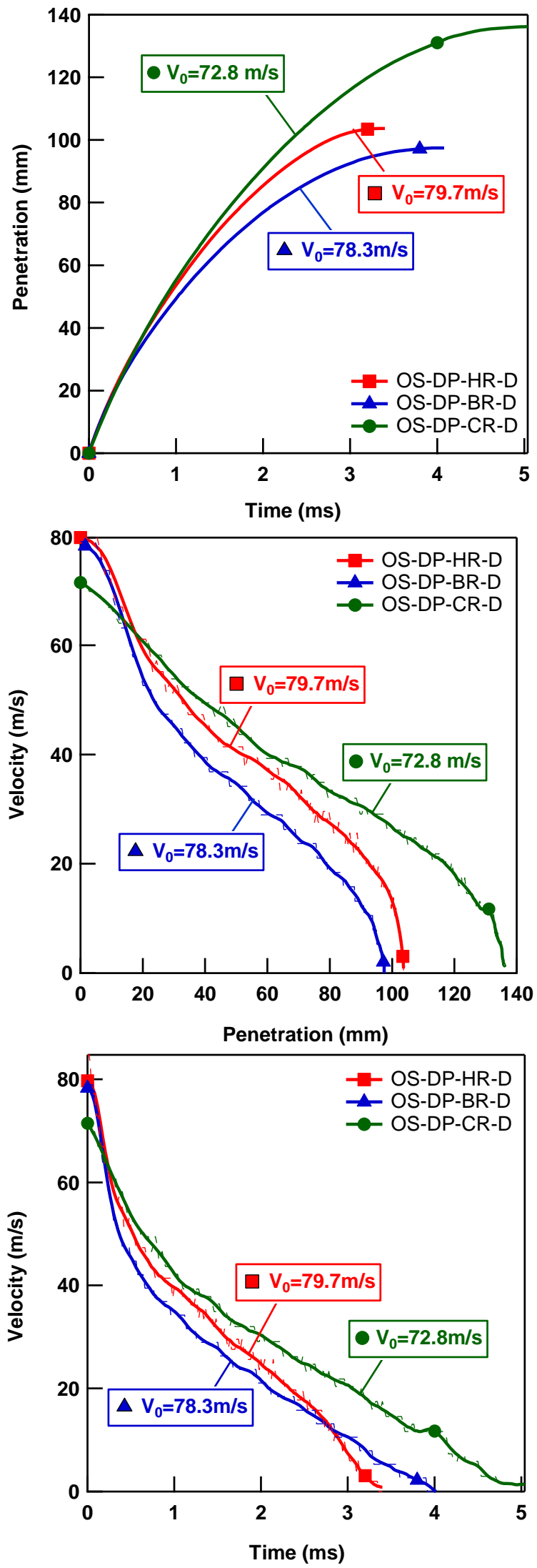

Fig 8: Effect of nose shape on penetration into dense Ottawa sand: (a) Penetration time history, (b) velocity vs. penetration, and (c) velocity vs. time (dashed lines represent raw data). 

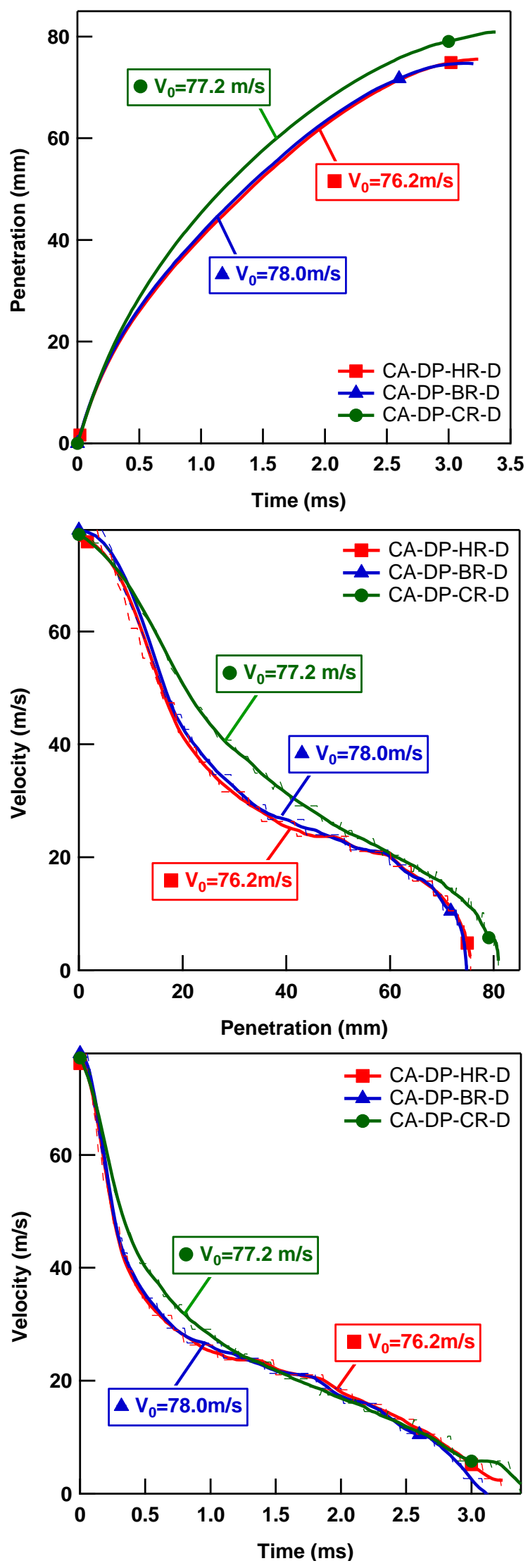

Fig 9: Effect of nose shape on penetration into dense Aragonite sand: (a) Penetration time history, (b) velocity vs. penetration, and (c) velocity vs. time (dashed lines represent raw data). 

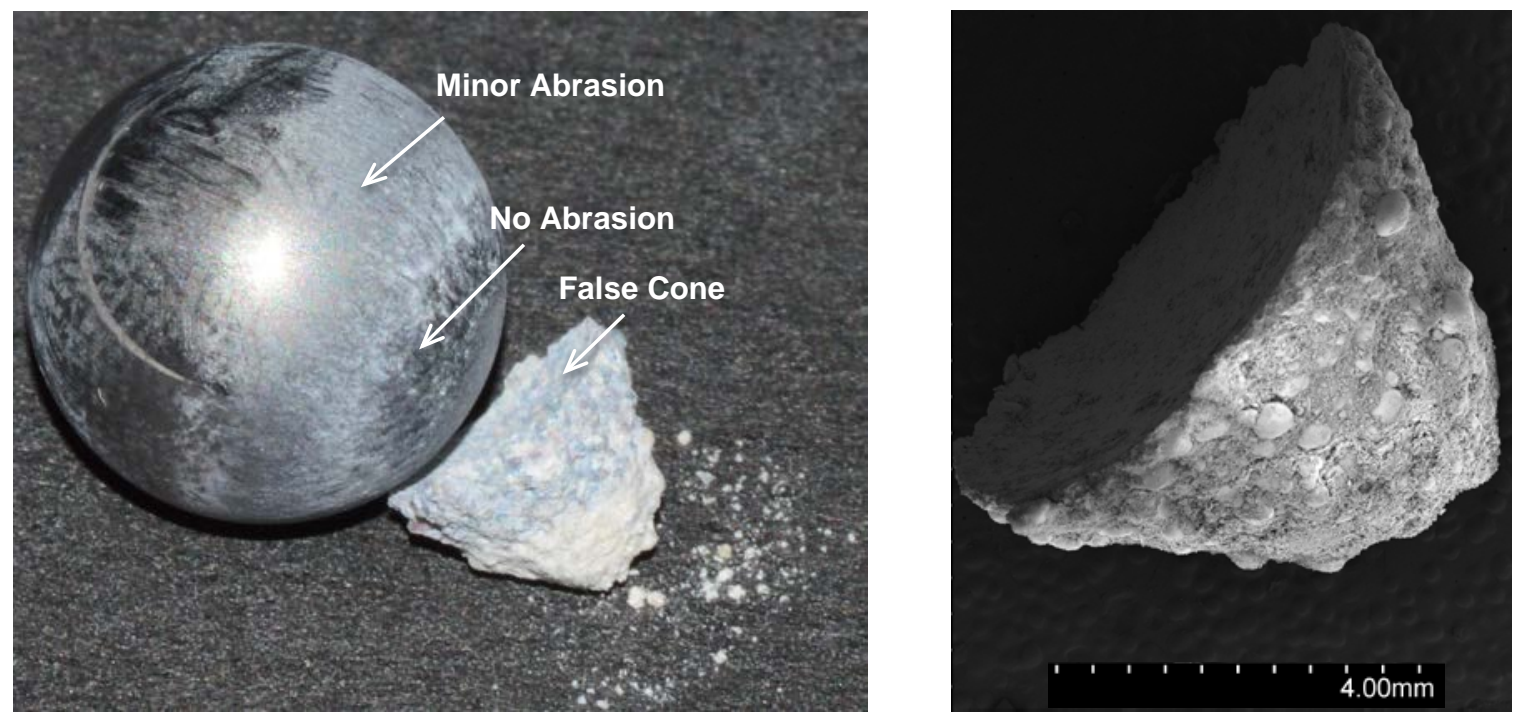

Fig 10: Image of false cone formed ahead of the projectile: (a) Spherical projectile and retrieved cone, (b) scanning electron microscope image of the false cone 


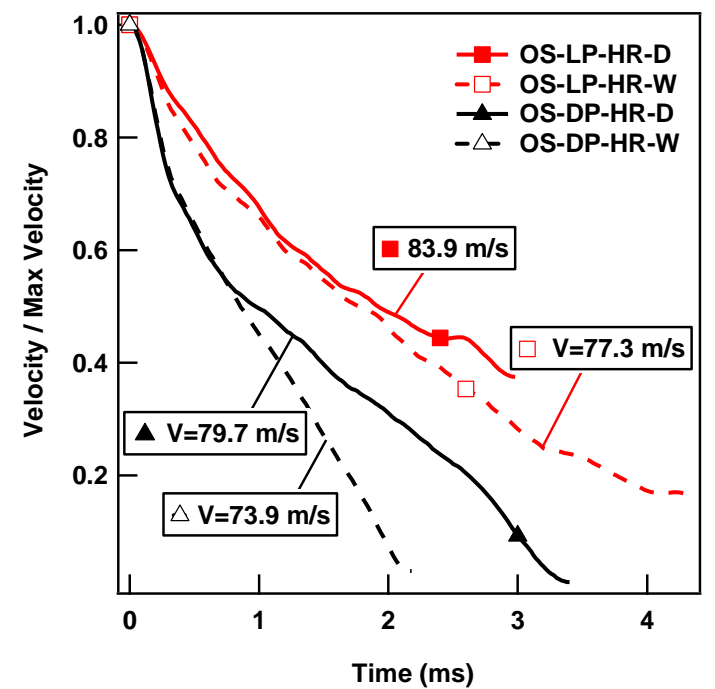

(a)

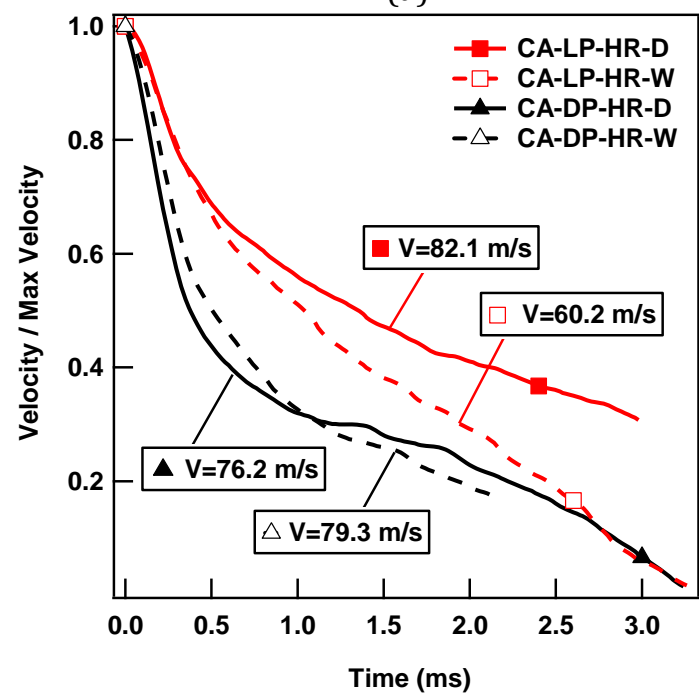

(c)

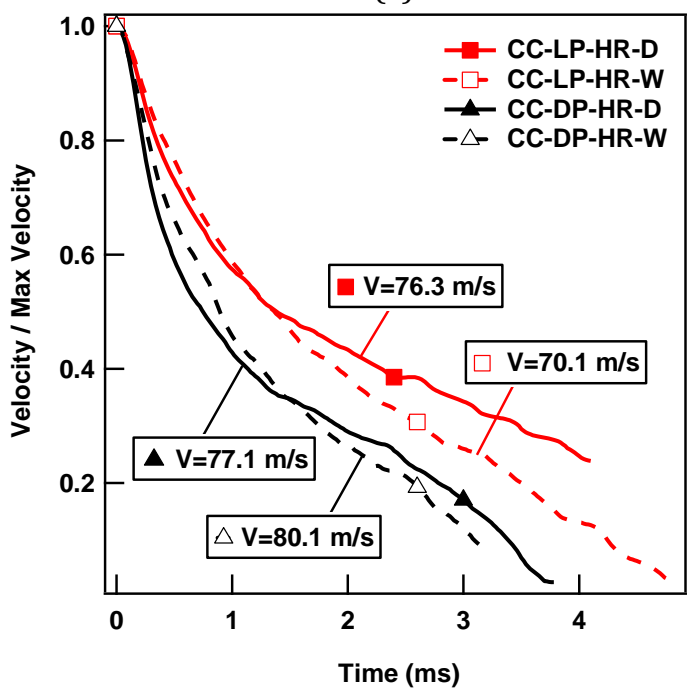

(e)

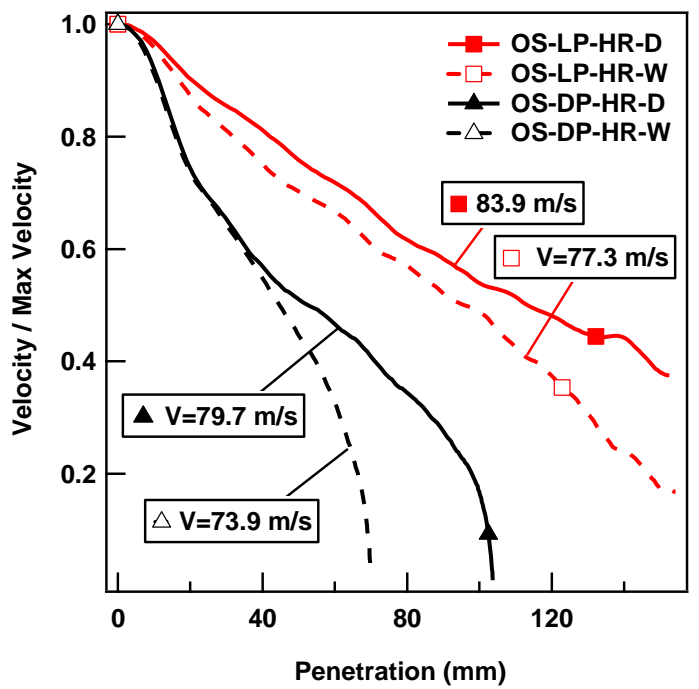

(b)

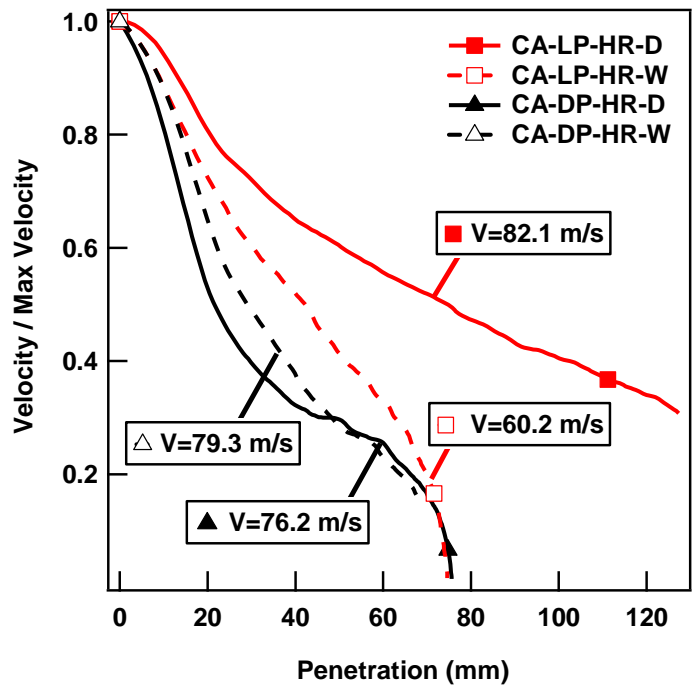

(d)

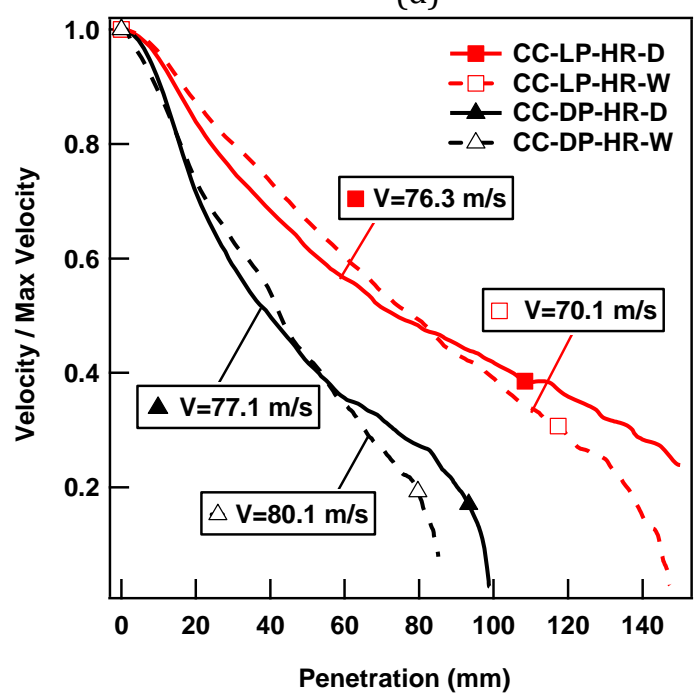

(f)

Fig 11: Effect of saturation on normalized velocity-time and penetration-time history of penetration into $(a, b)$ loose and dense Ottawa sand, (c, d) loose and dense aragonite sand, and (e, f) loose and dense crushed coral 

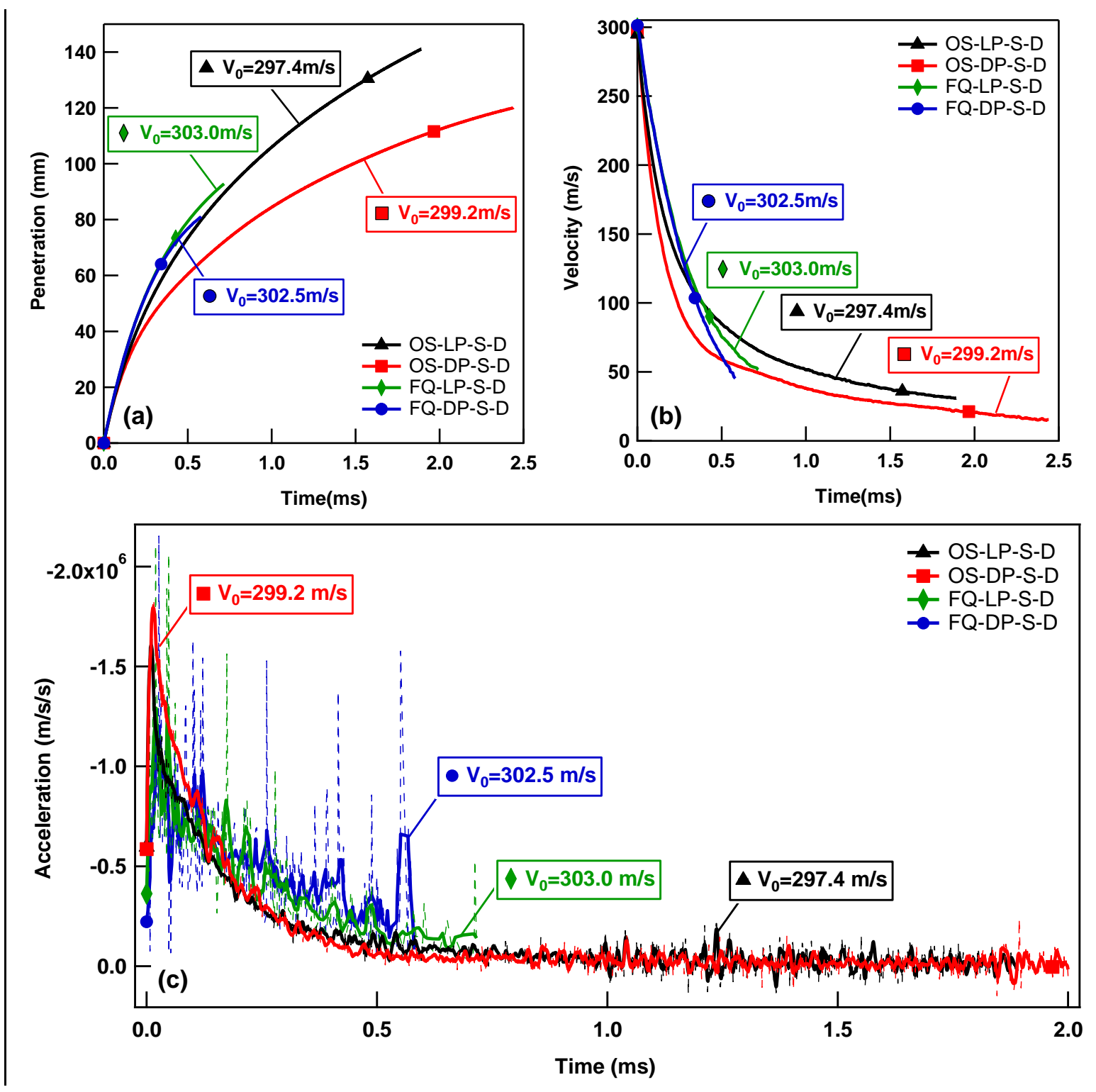

Fig 12: Penetration and velocity--time histories for high-speed tests; data collected using PDV (dashed lines represent raw data). 

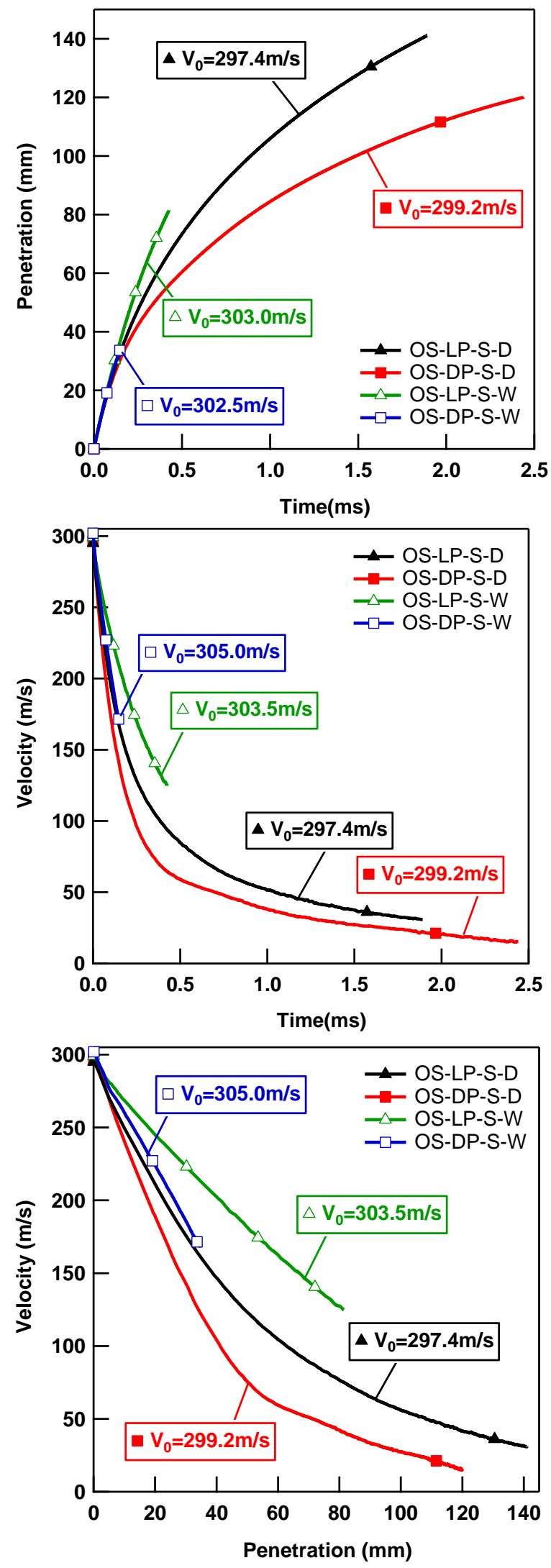

Fig 13: Comparison of wet and dry penetration time histories at high velocities; (a) Penetration time histories,

(b) Velocity time histories, and (c) Velocity vs. penetration 

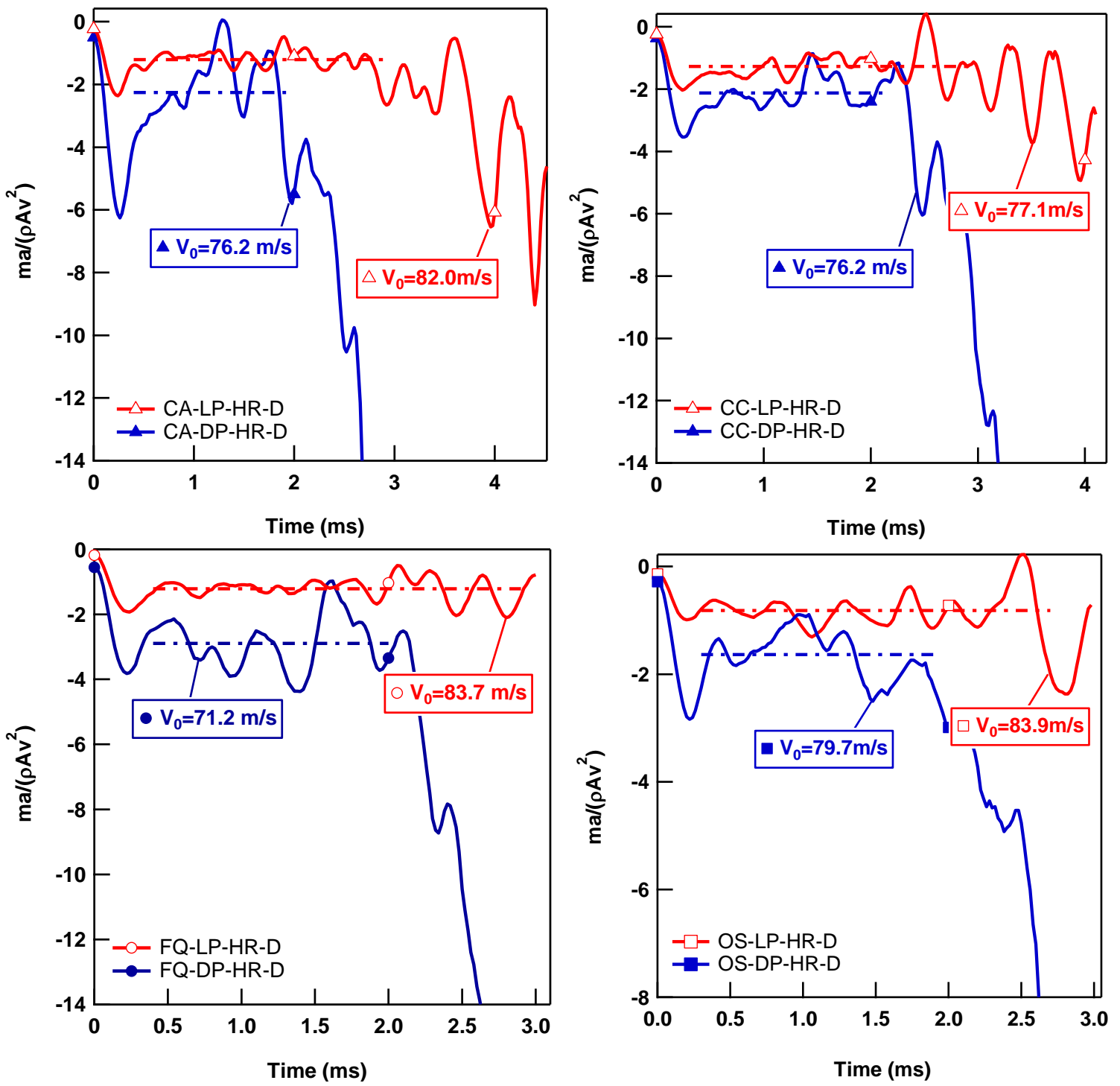

Fig 14: Time history of projected frontal nose pressure $(\mathrm{ma} / \mathrm{A})$ normalized by dynamic pressure $\left(\rho v^{2}\right)$ for penetration of hemispherical nose rods into targets (a) Ottawa sand, (b) Aragonite sand, (c) Crushed coral,

(d) Fused quartz. Normalization is by dynamic pressure, Apv2. Dashed lines are constant fits to the data, representing the drag coefficient. 


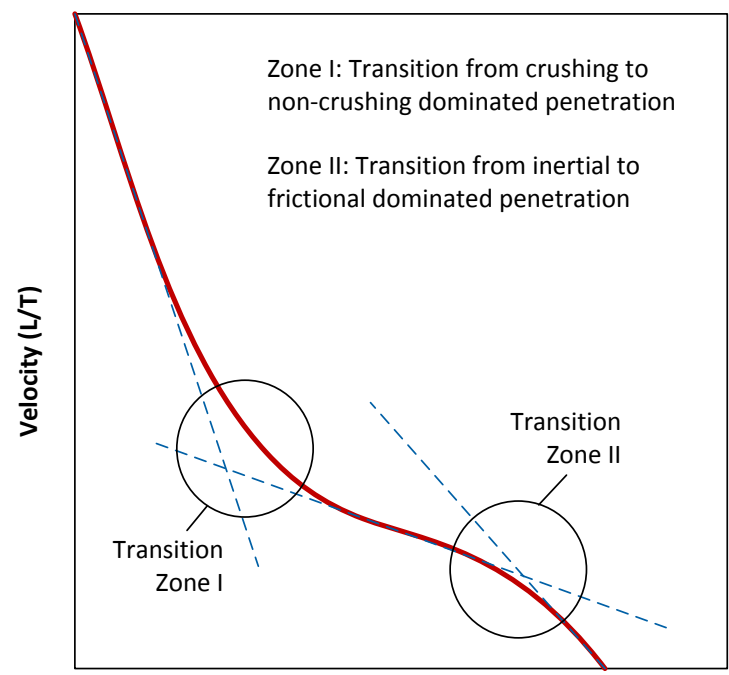

Penetration Depth (L)

Fig. 15 Schematic representation of velocity regimes during projectile penetration in granular media. 
Figure 16
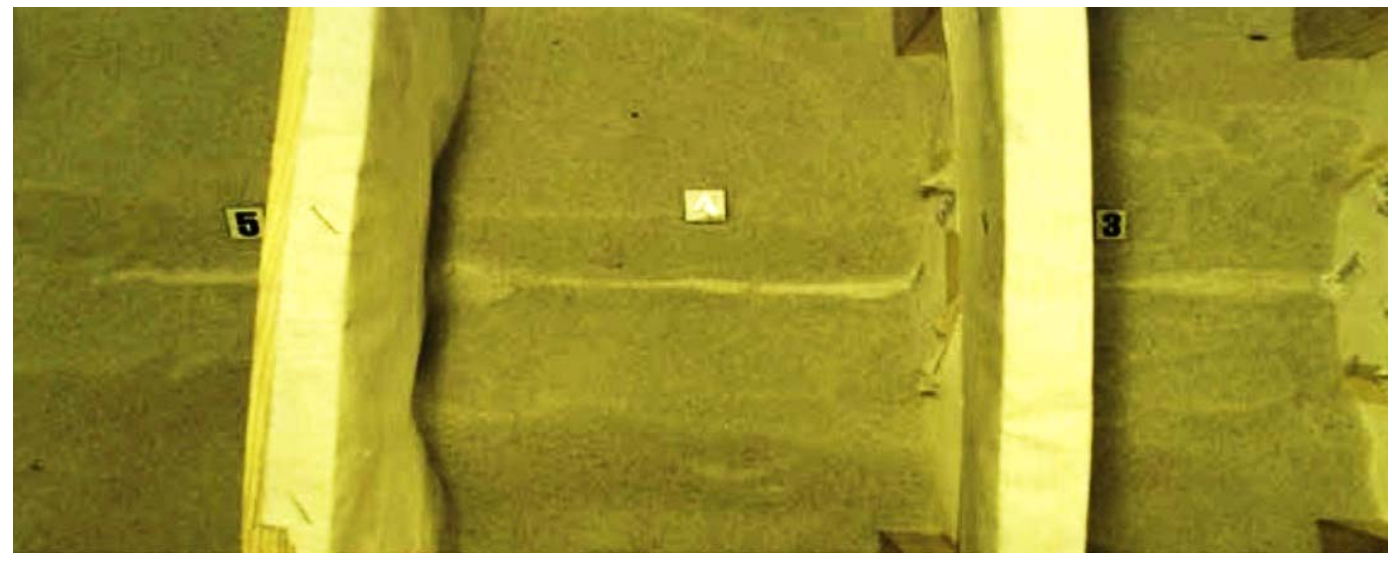

Fig 16: Trail of comminuted sand along the penetration trajectory from high velocity penetration tests (after Omidvar et al. 2014) 


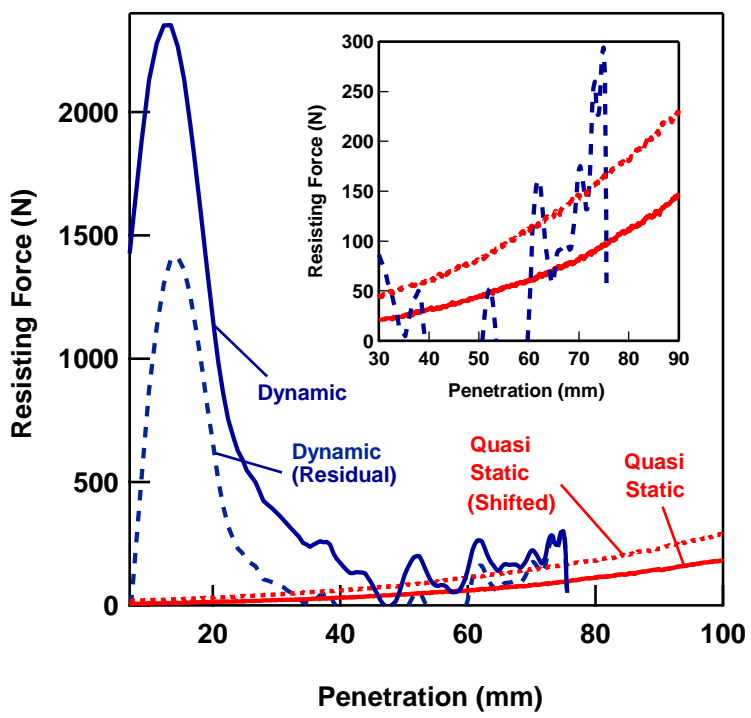

Fig 17: Comparison of dynamic and quasi static penetration resistance for dense aragonite sand (dashed line shows quasi static penetration resistance shifted on the horizontal axis by 3D) 


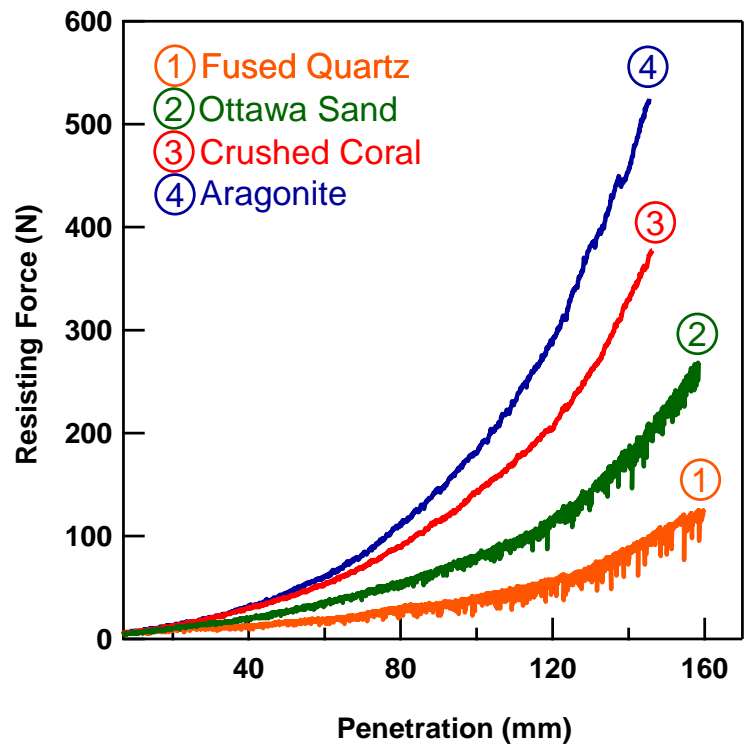

Fig 18: Quasi static penetration resistance of the four materials tested (penetration rate: $0.05 \mathrm{~mm} / \mathrm{s}$ ) 